OPEN ACCESS

Edited by: Yun-Qing Li, The Fourth Military Medical University, China

Reviewed by: Paul Manger, University of the Witwatersrand, South Africa Patrick A. Forcelli, Georgetown University, USA

*Correspondence: Francisco E. Olucha-Bordonau folucha@uji.es; folucha@uni.edu

${ }^{+}$Co-first authors.

Received: 30 November 2015 Accepted: 17 March 2016 Published: 07 April 2016

Citation:

Santos FN, Pereira CW Sánchez-Pérez AM, Otero-García M, Ma S, Gundlach AL and Olucha-Bordonau FE (2016) Comparative Distribution of Relaxin-3 Inputs and Calcium-Binding Protein-Positive Neurons in Rat Amygdala.

Front. Neuroanat. 10:36. doi: 10.3389/fnana.2016.00036

\section{Comparative Distribution of Relaxin-3 Inputs and Calcium-Binding Protein-Positive Neurons in Rat Amygdala}

\author{
Fabio N. Santos ${ }^{1,2 \dagger}$, Celia W. Pereira ${ }^{1,2 \dagger}$, Ana M. Sánchez-Pérez ${ }^{3}$, Marcos Otero-García ${ }^{1}$, \\ Sherie $\mathrm{Ma}^{4}$, Andrew L. Gundlach ${ }^{4,5}$ and Francisco E. Olucha-Bordonau ${ }^{1,3 *}$ \\ ${ }^{1}$ Departamento de Anatomía y Embriología Humana, Facultad de Medicina, Universitat Valencia, Valencia, Spain, ${ }^{2}$ Centro \\ de Ciências Biológicas e da Saúde, Universidade Tiradentes, Aracaju, Brazil, ${ }^{3}$ Unitat Predepartamental de Medicina, \\ Universitat Jaume I, Castellón, Spain, ${ }^{4}$ The Florey Institute of Neuroscience and Mental Health, Parkville, VIC, Australia, \\ ${ }^{5}$ Florey Department of Neuroscience and Mental Health and Department of Anatomy and Neuroscience, The University of \\ Melbourne, Melbourne, VIC, Australia
}

The neural circuits involved in mediating complex behaviors are being rapidly elucidated using various newly developed and powerful anatomical and molecular techniques, providing insights into the neural basis for anxiety disorders, depression, addiction, and dysfunctional social behaviors. Many of these behaviors and associated physiological processes involve the activation of the amygdala in conjunction with cortical and hippocampal circuits. Ascending subcortical projections provide modulatory inputs to the extended amygdala and its related nodes (or "hubs") within these key circuits. One such input arises from the nucleus incertus (NI) in the tegmentum, which sends amino acid- and peptide-containing projections throughout the forebrain. Notably, a distinct population of GABAergic $\mathrm{NI}$ neurons expresses the highly-conserved neuropeptide, relaxin-3, and relaxin-3 signaling has been implicated in the modulation of reward/motivation and anxiety- and depressive-like behaviors in rodents via actions within the extended amygdala. Thus, a detailed description of the relaxin-3 innervation of the extended amygdala would provide an anatomical framework for an improved understanding of $\mathrm{NI}$ and relaxin-3 modulation of these and other specific amygdalarelated functions. Therefore, in this study, we examined the distribution of NI projections and relaxin-3-positive elements (axons/fibers/terminals) within the amygdala, relative to the distribution of neurons expressing the calcium-binding proteins, parvalbumin (PV), calretinin (CR) and/or calbindin. Anterograde tracer injections into the $\mathrm{NI}$ revealed a topographic distribution of $\mathrm{NI}$ efferents within the amygdala that was near identical to the distribution of relaxin-3-immunoreactive fibers. Highest densities of anterogradelylabeled elements and relaxin-3-immunoreactive fibers were observed in the medial nucleus of the amygdala, medial divisions of the bed nucleus of the stria terminalis (BST) and in the endopiriform nucleus. In contrast, sparse anterogradely-labeled and relaxin-3-immunoreactive fibers were observed in other amygdala nuclei, including the lateral, central and basal nuclei, while the nucleus accumbens lacked any innervation. Using synaptophysin as a synaptic marker, we identified relaxin-3 positive synaptic terminals in the medial amygdala, BST and endopiriform nucleus of amygdala. 
Our findings demonstrate the existence of topographic $\mathrm{Nl}$ and relaxin-3-containing projections to specific nuclei of the extended amygdala, consistent with a likely role for this putative integrative arousal system in the regulation of amygdala-dependent social and emotional behaviors.

Keywords: anxiety, arousal, emotion, motivation, neuropeptide, nucleus incertus, social behavior, theta rhythm

\section{INTRODUCTION}

The amygdala is considered a central node for processing adaptive social and emotional behavior (Aggleton, 1993; Phelps, 2006; Adolphs, 2008). Sensory information arising from cerebral cortex and thalamus enters the amygdala where information acquires emotional value (LeDoux, 2000). In addition, amygdala function extends beyond Pavlovian-like fear conditioning with a role for amygdala processing described in valence (positive and negative affective), reward, decision-making and recognition of emotional facial expressions (Benarroch, 2015). In rodents, olfactory information from the main and accessory olfactory bulbs enters the amygdala where conspecific and allospecifics are recognized and social interactions are evaluated (Scalia and Winans, 1975; Ferguson et al., 2001; Pro-Sistiaga et al., 2007; Trainor et al., 2010). Other telencephalic inputs to the amygdala that originate in prefrontal cortex (McDonald, 1998; Vertes, 2004) and hippocampus (Canteras and Swanson, 1992) shape emotional processing by adding information to past emotional experiences or the context in which emotional experiences takes place (Sierra-Mercado et al., 2011). Intrinsic connections between amygdala subnuclei convey information to amygdala outputs (Pitkänen et al., 1997; Jolkkonen and Pitkänen, 1998; Schmitt et al., 2012). These connections are filtered/modulated by intrinsic GABAergic circuits (Sun and Cassell, 1993) and most GABAergic neurons in the amygdala contain the calcium-binding proteins, parvalbumin $(\mathrm{PV})$, calbindin $(\mathrm{CB} 28 \mathrm{kD})$ or calretinin (CR; McDonald and Mascagni, 2001).

The amygdala is strongly innervated by projections arising from a variety of monoamine neuron populations in the brainstem. For example, serotoninergic afferents are dispersed across multiple regions of the amygdala (Steinbusch, 1981; Smith and Porrino, 2008; Bonn et al., 2013). Arousal and stress induce an increase in serotonin concentrations in the amygdala during fear conditioning (Kawahara et al., 1993; Yokoyama et al., 2005; Mo et al., 2008; Christianson et al., 2010) and serotonin transporter inhibitors (SSRIs) are used to treat amygdala-related disorders, including anxiety, panic and phobias (Sheehan et al., 1993; Gorman, 2003). SSRIs induce increases in serotonin levels in amygdala (Bosker et al., 2001) and increased expression of the serotonin transporter in the amygdala reduces fear (Bocchio et al., 2015). This increased expression of serotonin transporter results in reduction of fear and produces impairment of recruitment of amygdala PV neurons (Bocchio et al., 2015). In contrast, catecholaminergic afferents specifically target the intercalated nuclei (Asan, 1998), which are important for conveying information from the prefrontal cortex to the central nucleus, subserving different aspects of processing extinction memories (Quirk et al., 2003). Dopaminergic cells of the lateral part of the ventral tegmental area and dorsal edge of the substantia nigra pars compacta innervate the amygdala, targeting mainly the intercalated nuclei (Loughlin and Fallon, 1983; Asan, 1998), and dopamine D2 receptor agonist infusion into the amygdala impairs the recall of fear memories (Nader and LeDoux, 1999). In addition, noradrenergic inputs to the amygdala contribute to the reconsolidation of fear memories (Debiec and LeDoux, 2006; Chen and Sara, 2007), and enhancement of noradrenergic transmission impairs extinction of conditioned fear (Debiec et al., 2011). Furthermore, drugs that modify monoaminergic signaling and metabolism have been widely used for many years as treatments of psychiatric disorders, such as anxiety, posttraumatic stress disorders, schizophrenia and autism (e.g., Carlsson and Lindqvist, 1963; Creese et al., 1976; Mailman and Murthy, 2010; Dinnissen et al., 2015). Further in this regard, some studies have reported structural changes in the amygdala in autistic patients. Children with autism have larger amygdala volumes than controls, but during adolescence, volumes become similar in both groups, which indicates an abnormal program of early development of the amygdala in autism (Schumann et al., 2004; Schumann and Amaral, 2006).

The nucleus incertus (NI) in the pontine tegmentum is another source of afferents to the main amygdala including its extended part (Olucha-Bordonau et al., 2003). Projections from the NI to telencephalic emotional processing centers run in parallel with ascending monoamine pathways from the locus coeruleus, raphe nuclei and the ventral tegmental area (AstonJones et al., 1986; Vertes and Kocsis, 1994; Vertes et al., 1999) and target similar areas including the septum, hippocampus, amygdala and prefrontal cortex. The NI is primarily composed of GABAergic neurons (Olucha-Bordonau et al., 2003; Ma et al., $2007)$, including a population $(\sim 30-50 \%)$ that expresses the neuropeptide, relaxin-3 (Tanaka et al., 2005; Ma et al., 2007). Relaxin-3 is the ancestral gene/peptide of the relaxin and insulinlike peptide superfamily, and is highly conserved throughout all vertebrate taxa (Wilkinson and Bathgate, 2007). The cognate $\mathrm{G}_{\mathrm{i} / \mathrm{o}}$-protein coupled receptor for relaxin-3 is relaxin family peptide receptor-3, or RXFP3 (also known as GPCR135 and SALPR (Liu et al., 2003; Boels et al., 2004), which is highly expressed within medial and central nuclei of the rat amygdala (Sutton et al., 2004; Ma et al., 2007). Experimental studies in the rat and other species implicate the NI relaxin-3/RXFP3 system in the integrated regulation of arousal/vigilance, stress responses, and associated homeostatic, emotional and cognitive processes (Tanaka et al., 2005; Banerjee et al., 2010; Smith et al., 2011, 2014; Ganella et al., 2013; Ma and Gundlach, 2015). 
Acquisition and retrieval of fear memories is reflected by coherent hippocampal and amygdala neuronal activity at theta frequency (4-12 Hz oscillations), also known as theta rhythm (Lesting et al., 2011). Notably, the NI has been demonstrated to modulate hippocampal theta rhythm (Nuñez et al., 2006; Ma et al., 2009), and relaxin-3 neurons in the NI preferentially fire in the early phase of theta oscillations (Ma et al., 2013). It is well established that hippocampal theta rhythm is strongly associated with arousal and exploration (O'Keefe, 1993) and interactions between the hippocampus and the amygdala support the contextual memory components of amygdala-dependent fear conditioning (Sierra-Mercado et al., 2011). In this sense, we have demonstrated that NI lesions result in impaired extinction of conditioned fear (Pereira et al., 2013). Acquisition of fear conditioning was not altered, but NI-lesioned rats exhibited significantly delayed extinction and a stronger freezing response, consistent with disruption of amygdala function and its established regulation of the acquisition and extinction of fear memories (Sierra-Mercado et al., 2011).

The relaxin-3/RXFP3 system has also been linked with modulation of feeding and motivated behaviors. Acute and chronic activation of RXFP3 increases food intake and weight gain in rats (McGowan et al., 2006; Ganella et al., 2013), and the effects of relaxin-3 on feeding behavior are dependent on stress levels and are sex- and species-dependent (Lenglos et al., 2013; Smith et al., 2014). In addition, rats fed with a high-fat diet exhibit differential RXFP3 expression in the medial and central nuclei of the amygdala (Lenglos et al., 2014). Disruption of relaxin-3/RXFP3 signaling impairs motivated food seeking and consumption in mice (Smith et al., 2014); and in an alcoholpreferring (iP) rat strain, icv infusion of the RXFP3 antagonist, $\mathrm{R} 3(\mathrm{~B} 1-22) \mathrm{R}$, or local infusion of R3(B1-22)R into the bed nucleus of the stria terminalis (BST) attenuates stress-induced relapse behavior (Ryan et al., 2013b).

Together, existing data suggest relaxin-3/RXFP3 signaling modulates affective behavior and emotionality, and although the existence of a relaxin-3 innervation of the rat amygdala has been reported (Ma et al., 2007), details of the specific innervation of the various nuclei and subnuclei have not been described. Given the functionally distinct nature of the different amygdala regions (Aggleton, 1993; Davis, 2000; Martínez-García et al., 2012; Olucha-Bordonau et al., 2014), this study aimed to examine the pattern of relaxin-3-immunoreactive afferent fibers, in relation to the delineation of the amygdala nuclei provided by the calcium-binding proteins, PV, CB-28kD and CR (Paxinos et al., 2008).

\section{MATERIALS AND METHODS}

\section{Animals}

Male Sprague-Dawley rats (300-400 g, $n=22$ ) were used in this study. All protocols were approved by the Animal Ethics Committee of the Universitat de València (Spain). All procedures were in line with directive 86/609/EEC of the European Community on the protection of animals used for experimental and other scientific purposes.

\section{Anterograde Tracer Injections}

Rats $(n=4)$ were anesthetized with a combination of ketamine (55 mg/kg i.p., Imalgene, Merial Labs, Barcelona, Spain) and xylacide (20 mg/kg i.p., xilagesic; Lab. Calier, Barcelona, Spain) and trephine holes were drilled in the skull. Anterograde tracer injections into the NI were made using $40 \mu \mathrm{m}$ I.D. glass micropipettes (coordinates from Bregma: AP $-9.6 \mathrm{~mm}, \mathrm{ML}$ $0 \mathrm{~mm}$ and DV $7.4 \mathrm{~mm}$ ). For anterograde tracing, 15\% miniruby $(\mathrm{mR}, 10 \mathrm{kD}$ biotinylated dextran amine (BDA) rhodaminelabeled; Molecular Probes, Paisley, UK; $n=2$, Figure 1A) or biotinylated dextran amine (BDA, $10 \mathrm{kD}$; Molecular Probes, Eugene, OR, USA; $n=2$, Figure 1B) dissolved in $0.1 \mathrm{M}$ phosphate buffer (PB), pH 7.6 was iontophoretically delivered into the NI by passing a positive current of $1 \mu \mathrm{A}, 2 \mathrm{~s}$ on $2 \mathrm{~s}$ off through the micropipette, over $10 \mathrm{~min}$. The micropipette was left in place for a further $10 \mathrm{~min}$ before withdrawal. After injections, the surgical wound was sutured and rats were injected with Buprex (0.05 mg/kg, i.p., Lab Esteve, Barcelona, Spain) for analgesia. Rats were then allowed to recover for at least 7 days, prior to further processing.

\section{Brain Fixation and Sectioning}

For analysis of tracing studies, IF and ICC, $(n=18)$ rats were deeply anesthetized with Nembutal (150 mg/kg i.p., Euthalender, Barcelona, Spain) and transcardially-perfused with saline $(250 \mathrm{ml})$ followed by fixative $(\sim 500 \mathrm{ml}$ of $4 \%$ paraformaldehyde in $0.1 \mathrm{M} \mathrm{PB}, \mathrm{pH}$ 7.4). Brains were dissected and immersed in the same fixative for $4 \mathrm{~h}$ at $4^{\circ} \mathrm{C}$ followed by incubation in $30 \%$ sucrose in $0.01 \mathrm{M} \mathrm{PBS} \mathrm{pH} 7.4$ for $48 \mathrm{~h}$ at $4^{\circ} \mathrm{C}$. Coronal sections $(40 \mu \mathrm{m})$ were collected using a freezing slide microtome (Leica SM2010R, Leica Microsystems, Heidelberg, Germany). For each brain, six series of sections were obtained and collected free-floating in $0.01 \mathrm{M} \mathrm{PBS}$, and stored at $-40^{\circ} \mathrm{C}$ in $30 \%$ sucrose in $0.01 \mathrm{M}$ PBS.

\section{Immunohistochemistry for Relaxin-3 and Calcium-Binding Proteins}

For analysis of relaxin-3-immunoreactive fiber distribution in relation to neurochemical/anatomical markers of amygdala nuclei and subnuclei, double-label immunohistochemistry for relaxin-3 and a number of different proteins was conducted. The rabbit relaxin-3 antisera was produced at The Florey Institute of Neuroscience and Mental Health (Parkville, VIC, Australia) and has been characterized and widely used (Ma et al., 2007; Smith et al., 2010; Olucha-Bordonau et al., 2012). In cases where primary antibodies were raised in different host species (rabbit and mouse), a combination of both antibodies in a single primary antibody incubation was used. In cases where primary antibodies were from the same host species, sequential primary and secondary antibody incubations were separated by overnight rinsing. For single primary antibody incubations, sections were rinsed twice in Tris-buffered 0.05 $\mathrm{M}$ saline (TBS) $\mathrm{pH} 8.0$ and transferred to blocking solution (4\% normal donkey serum (NDS), 2\% bovine serum albumin (BSA) and $0.2 \%$ Triton X100 in TBS) for $1 \mathrm{~h}$ at room temperature. Sections were then transferred to primary antibody 

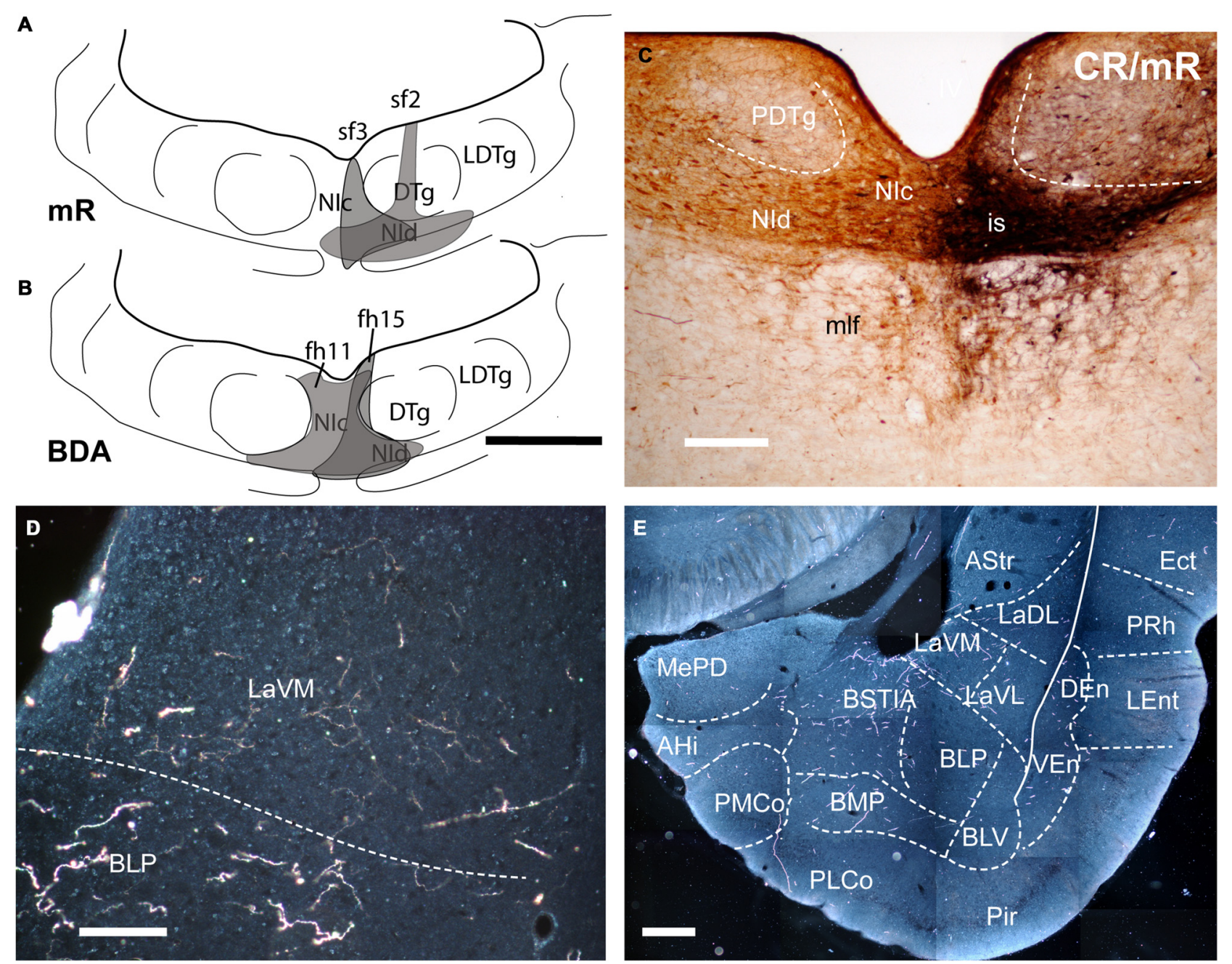

FIGURE 1 | Injection of an anterograde tracers, into the nucleus incertus (NI) and its transport to the amygdala. (A) Miniruby (mR) injection sites in the NI of cases sf2 and sf3. (B) Biotinylated dextran amine (BDA) injection sites in the NI in cases fh11 and fh15). (C) Site of mR injection in the NI of case sf2. (D) A darkfield image of the anterograde labeling in the ventromedial subnucleus of the lateral amygdala (LaVM) following a BDA injection into the NI (case fh11).

(E) A collage of darkfield images of anterogradely-labeled fibers in amygdala at a mid-caudal level. Dense NI projections were present in the intra-amygdala part of the stria terminalis (STIA) and LaVM (case fh11). Calibration bars, $500 \mu \mathrm{m}$ (A,B), $100 \mu \mathrm{m}$ (C), $200 \mu \mathrm{m}$ (D,E).

solution containing 1:2500 rabbit anti-relaxin-3 (Ma et al., 2007) and either 1:5000 mouse anti-parvalbumin (PV27; Swant 235, Swant, Bellinzona, Switzerland), 1:5000 mouse anti-calbindinD 28kD (CB38a; Swant), 1:2500 mouse anti-calretinin (CR 6B3; Swant), in TBS containing 2\% NDS, $2 \%$ BSA and $0.2 \%$ Triton $\mathrm{X} 100$ for $48 \mathrm{~h}$ at $4^{\circ} \mathrm{C}$. Relaxin-3 and neuronal markers were sequentially processed in secondary antibody and chromagen visualization.

For relaxin-3, sections were rinsed twice in TBS and incubated in 1:200 biotinylated donkey anti-rabbit antibody (711-065-152, Jackson Immunoresearch, West Grove, PA, USA) for $2 \mathrm{~h}$ at room temperature. Sections were then rinsed twice in TBS and transferred to 1:100 Avidin-Biotin-Complex (ABC) (Vectastain, Vector Laboratories, Burlingame, CA, USA). After rinsing $(2 \times$ TBS $)$ the immunolabeling was revealed as a black reaction product by immersing the sections in $0.025 \% 3,3^{\prime}$ diaminobenzidine (DAB; Sigma, St Louis, MO, USA), $0.5 \%$ ammonium nickel sulfate, $0.0024 \% \mathrm{H}_{2} \mathrm{O}_{2}$ in Tris $\mathrm{HCl}, \mathrm{pH} 8.0$. Sections were then rinsed for at least $2 \mathrm{~h}$. Amygdala markers were then revealed by incubation in appropriate biotinylated secondary antibody (1:200 biotinylated donkey anti-mouse, Jackson 715-065-150; or 1:200 biotinylated donkey anti-goat, Jackson 705-065-147) for $2 \mathrm{~h}$. Sections were then rinsed twice in TBS and incubated in 1:100 ABC for $1 \mathrm{~h}$. After rinsing $(2 \times$ TBS $)$ the immunolabeling was revealed as a brown reaction product by incubating the sections in $0.025 \% \mathrm{DAB} 0.0024 \%$ $\mathrm{H}_{2} \mathrm{O}_{2}$ in Tris $\mathrm{HCl}, \mathrm{pH}$ 7.6. Following several rinses in 0.01 M PBS, sections were mounted on chrom alum gelatin-coated slides, airdried, dehydrated with graded ethanol, cleared with xylene, and coverslipped with DPX (Sigma). 


\section{Immunofluorescence of Relaxin-3 and Calcium-Binding Proteins}

In studies of putative contacts between relaxin-3 fibers and neuronal somata and processes positive for calcium binding proteins, a mouse monoclonal relaxin-3 antibody was used in combination with rabbit antisera against calcium binding proteins. The monoclonal antibody against a recombinant relaxin-3 immunogen has been used previously (Tanaka et al., 2005; Ma et al., 2013) and the specificity of the antibody has been demonstrated using brain sections from relaxin3 gene knockout mice (Watanabe et al., 2011). For double immunofluorescence, sections were rinsed three times in PBS $0.01 \mathrm{M}$ and transferred to blocking solution (4\% normal goat serum (NGS), 2\% BSA and $0.1 \%$ Triton X100 in PBS) for $1 \mathrm{~h}$ at room temperature. Sections were then transferred to primary antibody solution containing 1:5 mouse anti-relaxin-3 (cell culture media) and either 1:5000 rabbit anti-parvalbumin (PV27; Swant 235, Swant), 1:10,000 rabbit anti-calbindin-D 28kD (CB38a; Swant), 1:2000 rabbit anti-calretinin (CR 7697; Swant), in PBS containing 2\% NGS, $2 \%$ BSA and $0.1 \%$ Triton X100 for $48 \mathrm{~h}$ at $4^{\circ} \mathrm{C}$. Relaxin-3 and neuronal markers were sequentially processed for the secondary antibody visualization steps. For relaxin-3, sections were rinsed twice in PBS and incubated in 1:400 goat anti-mouse-Alexa488 antibody (115-545-146, Jackson Immunoresearch) for $2 \mathrm{~h}$ at room temperature. Sections were then rinsed three times in PBS and transferred to a new solution for visualizing the calcium binding proteins. Thus, sections were transferred to 1:400 goat anti-rabbit-Cy3 antibody (111-165003, Jackson Immunoresearch) for $2 \mathrm{~h}$ at room temperature. Then sections were rinsed in PBS, mounted on clean slides and coverslipped with Fluoromount ${ }^{\mathrm{TM}}$ (F4680, Sigma).

\section{Immunofluorescence of Relaxin-3 and Synaptophysin}

For double-label immunofluorescence, sections were rinsed $2 \times 10 \mathrm{~min}$ and incubated in blocking media of TBS containing $4 \%$ NDS, $2 \%$ BSA and $0.1 \%$ Triton X-100 for $1 \mathrm{~h}$ at room temperature. Sections were then incubated in primary antibody solution containing 1:1250 rabbit anti-relaxin3 and 1:1000 mouse anti-synaptophysin (Sigma, S5768) in TBS containing 2\% NDS, $2 \%$ BSA and $0.2 \%$ Triton X100 for $48 \mathrm{~h}$ at $4^{\circ} \mathrm{C}$. Sections were then rinsed $(3 \times$ TBS $)$ and incubated in 1:200 Alexa488-conjugated donkey antimouse (Jackson Immunoresearch, 715-545-150) and 1:200 Cy3conjugated donkey anti-rabbit (Jackson Immunoresearch, 711165-152). Sections were then briefly rinsed in 0.01 M PBS and mounted on chrom alum gelatin-coated slides and coverslipped with Fluoromount ${ }^{\mathrm{TM}}$ (F4680, Sigma).

Quantification of colocalization of synaptophysin in relaxin3 fibers was conducted using sections double-reacted with the monoclonal relaxin-3 antibody and rabbit synaptophysin antisera (ab14692, Abcam, Cambridge, UK). Sections were rinsed three times in PBS $0.01 \mathrm{M}$ and transferred to blocking solution (4\% NGS, 2\% BSA and $0.1 \%$ Triton X100 in PBS) for $1 \mathrm{~h}$ at room temperature. Sections were then transferred to primary antibody solution containing 1:5 mouse anti-relaxin-3 and 1:400 rabbit anti-synaptophysin. For relaxin-3 visualization, sections were rinsed twice in PBS and incubated in 1:400 goat anti-mouse-Alexa488 antibody (Jackson Immunoresearch, 115-545-146) for $2 \mathrm{~h}$ at room temperature. For synaptophysin visualization, sections were rinsed $3 \times \mathrm{PBS}$ and transferred to a solution containing 1:400 goat anti-rabbit-Cy3 antibody (Jackson Immunoresearch, 111-165-003) for $2 \mathrm{~h}$ at room temperature. Then sections were rinsed in PBS, mounted on clean slides and coverslipped with Fluoromount $^{\mathrm{TM}}$ (F4680, Sigma).

\section{Immunohistochemistry Analyses}

$\mathrm{DAB}$ immunohistochemistry was examined and recorded using a Nikon Eclipse E600 microscope equipped with a DMX2000 digital camera (Nikon, Tokyo, Japan). Maps of antigen distribution were constructed using a camera lucida tube attached to a Zeiss Axioskop microscope (Zeiss, Munich, Germany) at $20 \times$ magnification. These were scanned and reduced to the final size for reproduction. Confocal immunofluorescence was analyzed with a laser confocal scan unit TCS-SP8 equipped with argon and helio-neon laser beams attached to a DMIRB inverted microscope (Leica Microsystems). For Cy3 fluorophore, excitation was $433 \mathrm{~nm}$ for 560-618 nm emission. For Alexa 488, excitation was $488 \mathrm{~nm}$ for $510-570 \mathrm{~nm}$ emission. Serial $0.3 \mu \mathrm{m}$ sections were imaged to assess colocalization of relaxin-3-immunoreactive terminals with synaptophysin, using Leica Confocal Software (V 2.61).

In $n=3$ cases, the co-localization of synaptophysin and relaxin-3 was analyzed in different amygdala divisions. Captured images using the $40 \times$ objective were taken through a total depth of $10 \mu \mathrm{m}$ and then reconstructed with the Leica application suite (LAS-X) software. Firstly, we studied the percentage of relaxin-3 fibers that does not co-localize with synaptophysin. Second, we studied the density of synaptophysin boutons along the length of relaxin-3 fibers.

\section{RESULTS}

The delineation of the different amygdala nuclei has been recently documented (Olucha-Bordonau et al., 2014; Paxinos and Watson, 2014) and based on these topographical descriptions, in this study we have considered three regions: the temporal amygdala (TA), the bed nucleus of the stria terminalis $\left(\mathrm{ST}^{1}\right)$ which corresponded to the dorsal extension, and the sublenticular extended amygdala (SLEA), which corresponded to the ventral extension. These divisions are based on topography to facilitate anatomical description, but do not correspond to functional or ontogenetic divisions. Notably, the lateral, basal and cortical nuclei are of pallial origin (Table 1), while the two extensions, together with the medial and central nuclei, constitute the medial and central extended amygdala,

\footnotetext{
${ }^{1}$ The bed nucleus of the stria terminalis has been classically abbreviated as BST or BNST, however the different sub-subdivisions of this complex make this unsuitable, thus following the 7th Edition of the Paxinos and Watson Atlas of the Rat Brain, we have adopted the simplified abbreviation of ST to refer to these nuclei.
} 
TABLE 1 | Distribution of anterogradely-labeled nucleus incertus (NI) fibers and relaxin-3-positive fibers in pallial nuclei of amygdala.

\begin{tabular}{|c|c|c|c|}
\hline & Nucleus/area & $\begin{array}{l}\text { Anterogradely-labeled } \\
\text { NI fibers }\end{array}$ & $\begin{array}{l}\text { Relaxin-3 } \\
\text { IR }\end{array}$ \\
\hline \multirow{11}{*}{$\begin{array}{l}\text { Cortical } \\
\text { pallial }\end{array}$} & Lateropallial & & \\
\hline & $\begin{array}{l}\text { Nucleus of the lateral olfactory } \\
\text { tract (LOT) }\end{array}$ & - & - \\
\hline & $\begin{array}{l}\text { Bed nucleus of the accessory } \\
\text { olfactory tract (BAOT) }\end{array}$ & - & - \\
\hline & $\begin{array}{l}\text { Cortex amygdala transition } \\
\text { zone }(\mathrm{CxA})\end{array}$ & - & - \\
\hline & $\begin{array}{l}\text { Amygdalopiriform transition } \\
\text { area (APir) }\end{array}$ & - & - \\
\hline & Dorsal endopiriform (DEn) & +++ & +++ \\
\hline & Ventral endopiriform (VEn) & +++ & +++ \\
\hline & Ventropallial & & \\
\hline & $\begin{array}{l}\text { Anterior cortical amygdaloid } \\
\text { nucleus (ACo) }\end{array}$ & - & - \\
\hline & $\begin{array}{l}\text { Posterolateral cortical amygdaloid } \\
\text { nucleus (PLCo) }\end{array}$ & - & - \\
\hline & $\begin{array}{l}\text { Posteromedial cortical } \\
\text { amygdaloid nucleus (PMCo) }\end{array}$ & - & - \\
\hline \multirow{15}{*}{$\begin{array}{l}\text { Deep } \\
\text { pallial }\end{array}$} & Lateropallial & & \\
\hline & Basolateral (BL) & & \\
\hline & Basolateral anterior nucleus (BLA) & + & + \\
\hline & $\begin{array}{l}\text { Basolateral posterior nucleus } \\
(\mathrm{BLP})\end{array}$ & ++ & ++ \\
\hline & $\begin{array}{l}\text { Basolateral ventral nucleus (BLV) } \\
\text { Basomedial }\end{array}$ & + & + \\
\hline & Basomedial anterior (BMA) & +++ & +++ \\
\hline & Basomedial posterior (BMP) & + & + \\
\hline & Ventropallial & & \\
\hline & Lateral (La) & & \\
\hline & Lateral dorsolateral part (LaDL) & + & + \\
\hline & Lateral ventrolateral part (LaVL) & ++ & ++ \\
\hline & Lateral medial part (LaM) & ++ & ++ \\
\hline & $\begin{array}{l}\text { Amygdalohippocampal transition } \\
\text { area }\end{array}$ & & \\
\hline & Posteromedial (AHiPM) & ++++ & ++++ \\
\hline & Anterolateral (AHiAL) & ++++ & ++++ \\
\hline
\end{tabular}

which are of sub-pallial origin (Table 2). We have used this hierarchy to analyze the occurrence of anterograde tracing and relaxin-3-immunoreactivity in different nuclei of the amygdala.

\section{Nucleus Incertus Projections to Amygdala}

We successfully made $\mathrm{BDA}(n=2)$ and $\mathrm{mR}(n=2)$ tracer injections that were restricted to the NI, with no spread of tracer to the adjacent dorsal tegmental nucleus or pontine raphe nucleus (Figures 1A-C). Anterogradely-labeled fibers in the amygdala detected with both tracers were thin and varicose (Figures 1D,E; data not shown), primarily occupying medial aspects of the TA (Figures 1D,E, 2), and medial aspects of ST and SLEA (Figures 3, 4).

\section{Temporal Amygdala (TA)}

Anterogradely-labeled fibers entering the amygdala complex appeared to originate from fiber tracts within the medial forebrain bundle and sublenticular area at rostral levels of the TA (Figure 2A). The densest areas of NI innervation occupied
TABLE 2 | Distribution of anterogradely-labeled NI fibers and relaxin-3 positive fibers in subpallial nuclei of amygdala.

\section{Nucleus/area}

Anterogradelylabeled NI fibers

Relaxin-3

\section{Medial nucleus (Me)}

Medial nucleus anterodorsal part (MeAD)

Medial nucleus anteroventral part (MeAV)

Medial nucleus posterodorsal part (MePD)

Medial nucleus posteroventral part (MePV)

Central nucleus (Ce)

Central nucleus medial division (CeM)

Central nucleus lateral division (CeL)

Central nucleus capsular division $(\mathrm{CeC})$

Amygdalostriatal transition area (ASt)

Anterior amygdaloid area (AA)

Intercalated nuclei (I)

Bed nucleus of the stria terminalis (ST)

Intraamygdala part (STIA)

Supracapsular part (STSC)

Medial anterior (STMA)

Medial ventral (STMV)

Lateral division (STL)

Lateral dorsal (STLD)

Lateral intermediate (STLI)

Lateral juxtacapsular (STLJ)

Lateral posterior (STLP)

Fusiform nucleus (Fu)

Parastriatal nucleus (PS)

Bed nucleus of the anterior commissure (BAC)

Sublenticular extended amygdala (SLEA)

Sublenticular substantia innominata (SI)

Interstitial nucleus of the

posterior limb of the anterior

commissure (IPAC)

the medial amygdala nuclei and a broad band between the basal lateral and cortical nuclei, which corresponded most closely to the basomedial nuclei. Labeled fibers were observed within the four nuclei of the medial amygdala-medial anterodorsal $(\mathrm{MeAD})$, medial anteroventral (MeAV), medial posterodorsal (MePD) and medial posteroventral (MePV; Figures 2B,C). However, in the MePD, the most medial region was devoid of labeled fibers, which were concentrated in the lateral aspects of this nucleus (Figure 2D). Most cortical amygdala nuclei were devoid of labeled fibers except for the inner parts. In contrast, a high density of fibers was observed in the anterior part of the basomedial nucleus (BMA; Figures 2A-D), whereas the posterior part (BMP) contained sparse anterograde labeling. The intra-amygdala part of the ST (STIA) contained a high density of labeled fibers (Figures 2B-D), with a differential distribution observed within the lateral and basolateral nuclei, along the rostrocaudal axis. While these nuclei contained sparse labeling at anterior levels, fibers were more concentrated at caudal levels, forming dense plexuses in the basolateral posterior nucleus (BLP), lateral medial part (LaM) and lateral ventrolateral part (LaVL) of the ventropallidal amygdala (Figures 2E,F). At these caudal levels, a high density of fibers was also observed in the anterolateral (AHiAL) and posteromedial (AHiPM) parts of the amygdalohippocampal transition area (Figure 2F). Sparse labeling was observed in 
A

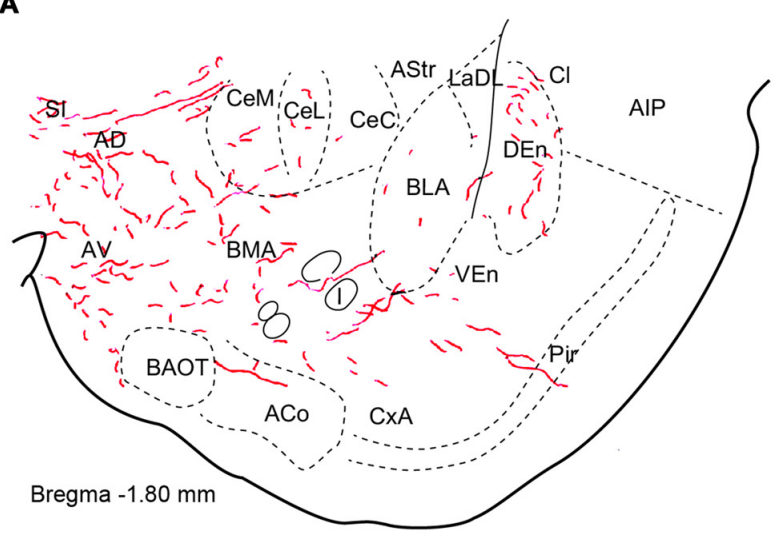

B

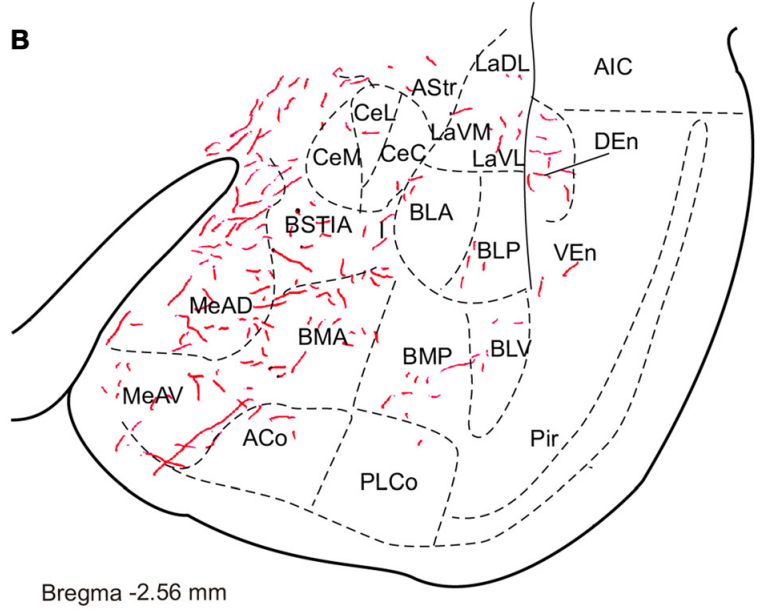

D
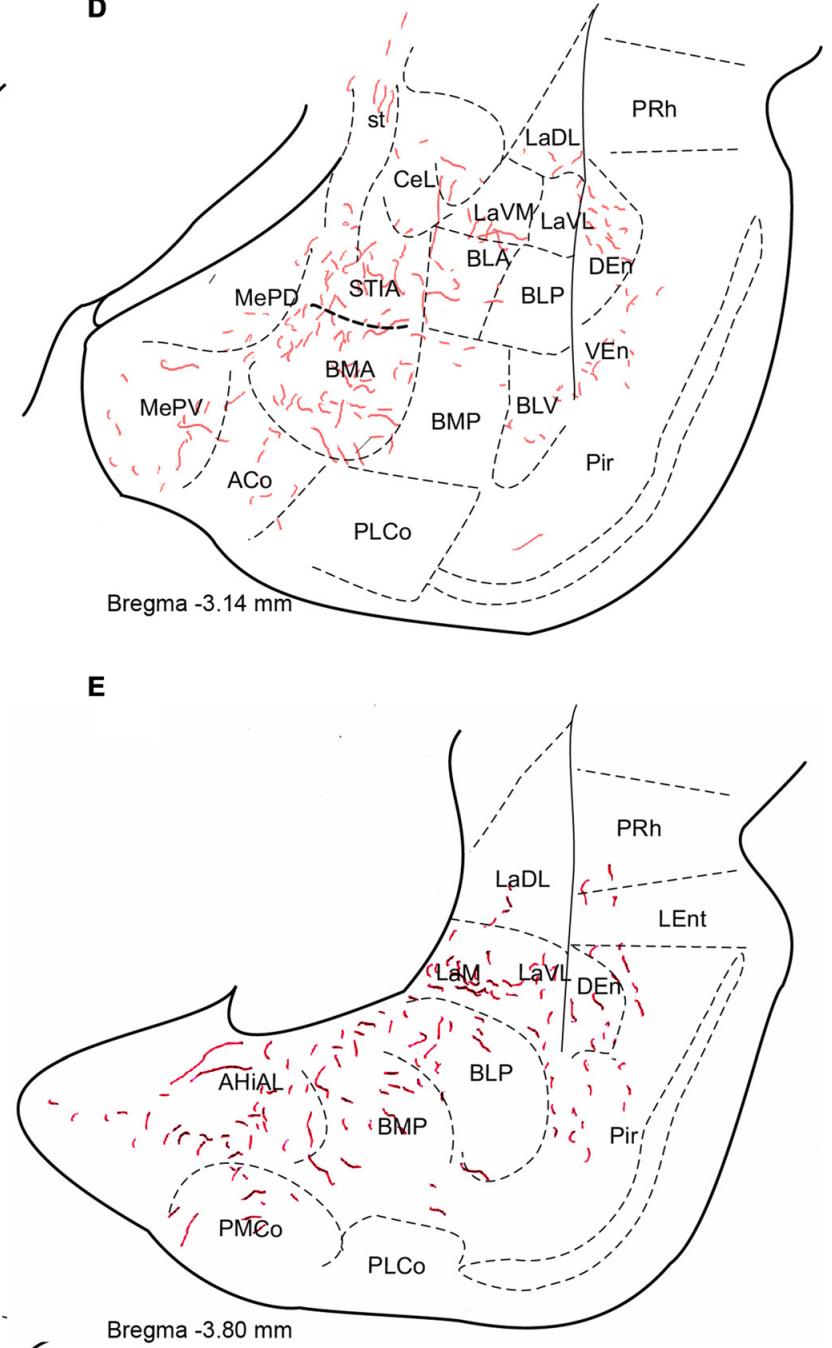

C

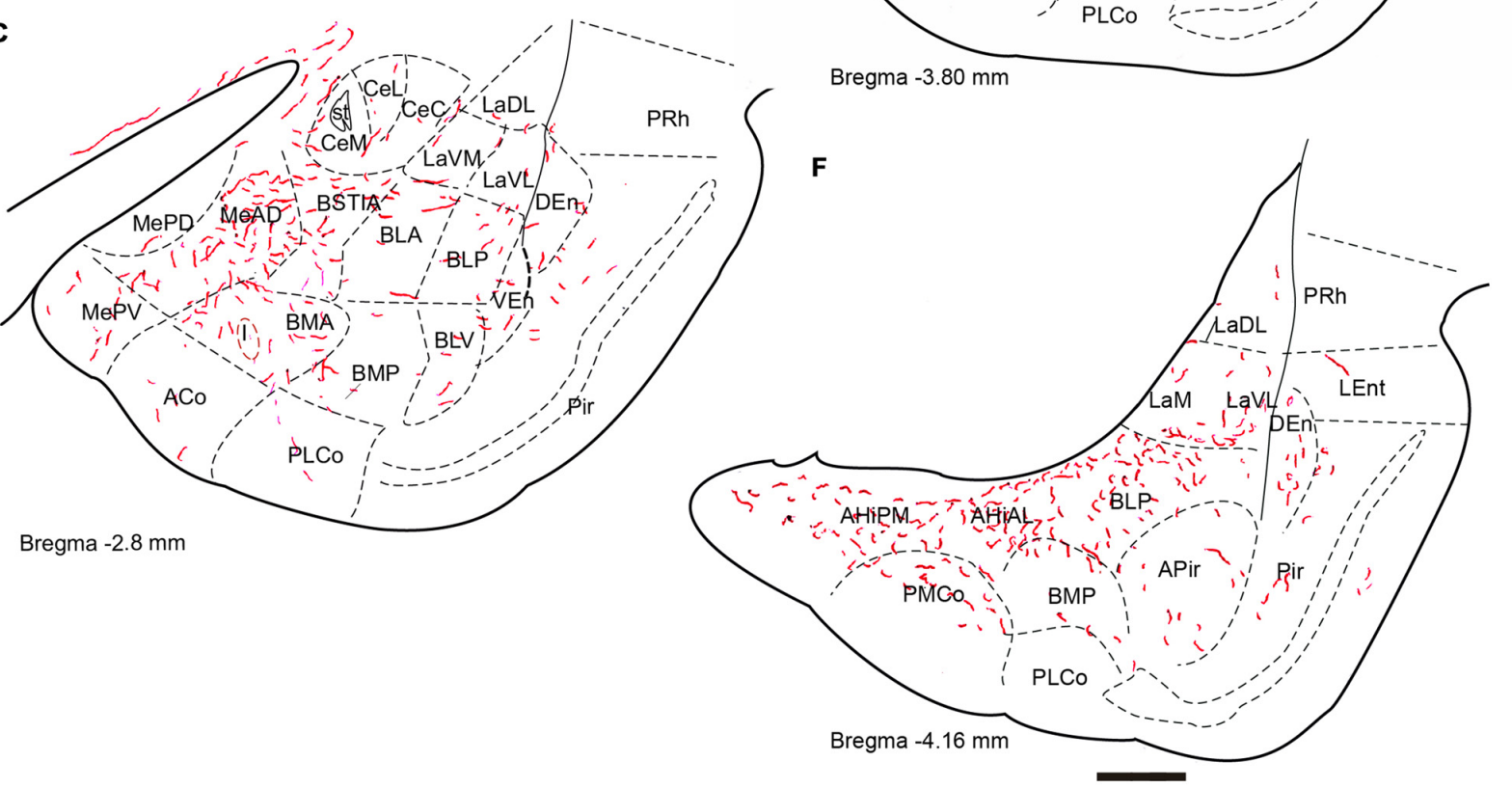

FIGURE 2 | Distribution of anterograde fiber labeling in the temporal amygdala (TA) from a case with a BDA injection into the NI. Labeled fibers occurred mainly in the medial aspects of the themporal amygdala and in a broad band in the basal nuclei. (A-F) Represents camera lucida drawings of the corresponding bregma levels. Calibration bar $500 \mu \mathrm{m}$. 
the posteromedial cortical amygdala nucleus (PMCo), and the amygdalopiriform transition area (APir) was devoid of any innervation.

Anterogradely-labeled fibers (BDA and $\mathrm{mR}$ ) were observed crossing the basomedial nuclei to innervate lateral aspects of the basolateral ventral nucleus (BLV) and the endopiriform nuclei, giving rise to dense plexuses in both the DEn and ventral endopiriform nuclei (VEn; Figures 2B-D, Table 1).

\section{Nuclei of the Stria Terminalis (ST)}

In the ST, anterogradely-labeled fibers were primarily observed in the medial aspects at all rostrocaudal levels (Figures 3A-C). At rostral and middle levels, fibers were observed in the anterior (STMA) and ventral (STMV) nuclei of the medial nucleus of the ST, encircling the anterior commissure bundles (Figures $3 \mathrm{~A}, \mathrm{C}$ ), and dispersed fibers were also observed in the lateral nuclei of the ST. At caudal levels, labeled plexuses were observed in the posterior medial (STMPM), posterior intermediate (STMPI) and posterior lateral (STMPL) parts of the medial nucleus of the ST (Figure 3C). No labeling was observed in any lateral nuclei at these caudal levels.

\section{Sublenticular Extended Amygdala}

At anterior levels of the TA, a dense plexus of labeled fibers was observed in the lateral preoptic area (LPO) and horizontal limb of the diagonal band. In addition, some fibers ran laterally to the anterior amygdala nuclei. Some fibers were observed in the ventral (AAV) and dorsal (AAD) divisions of the anterior amygdala nuclei, where fibers ran rostrally and dorsally to innervate the sublenticular substantia innominata (Figures 4A,B). Disperse fibers were also observed in the basomedial nuclei of the amygdala and the interstitial nucleus of the posterior horn of the anterior commissure (IPAC; Figures 4A,B).

\section{Distribution of Relaxin-3 Fibers within the Amygdala}

The distribution of relaxin-3-immunopositive fibers was similar to that observed with anterograde-tracer labeling of NI inputs to the amygdala. In order to identify the nature of target neurons within the different amygdala nuclei, we used doublelabel immunofluorescence for relaxin-3 and the calciumbinding proteins, PV, calbindin-28kD (CB-28kD) and CR (Figures 5, 6, 7).

\section{Relaxin-3 Innervation of Temporal Amygdala (TA)}

Six rostrocaudal levels of the amygdala, from $-2.2 \mathrm{~mm}$ to $-3.6 \mathrm{~mm}$ relative to Bregma (Paxinos and Watson, 2014), were assessed in these studies. In an effort to better describe the distribution pattern observed, amygdala nuclei and subnuclei were delineated using the distribution of PV, CB-28kD and CR immunoreactivity. In general, $\mathrm{PV}-\mathrm{CB}-28 \mathrm{kD}$ and $\mathrm{CR}$-positive cells appeared dispersed in the amygdala areas derived from a cortical-pallial origin, thus representing good landmarks for the boundary between pallium and subpallium.

Strong PV labeling was present in the neuropil of the BLA and BLP nuclei (data not shown), which clearly differentiates

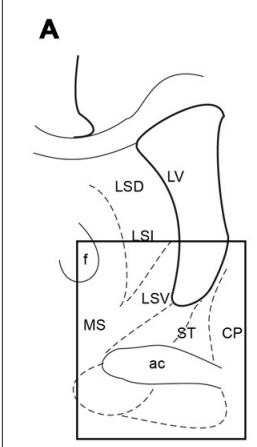

Bregma $+0.12 \mathrm{~mm}$

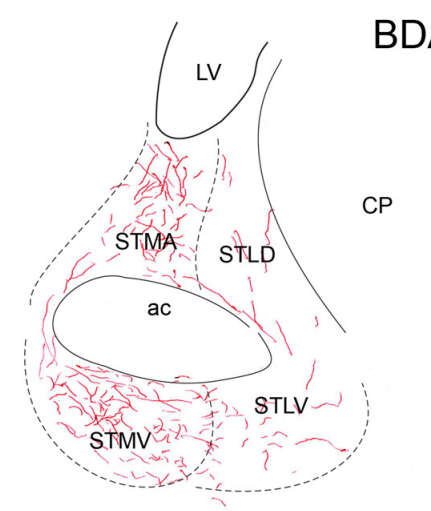

BDA

B
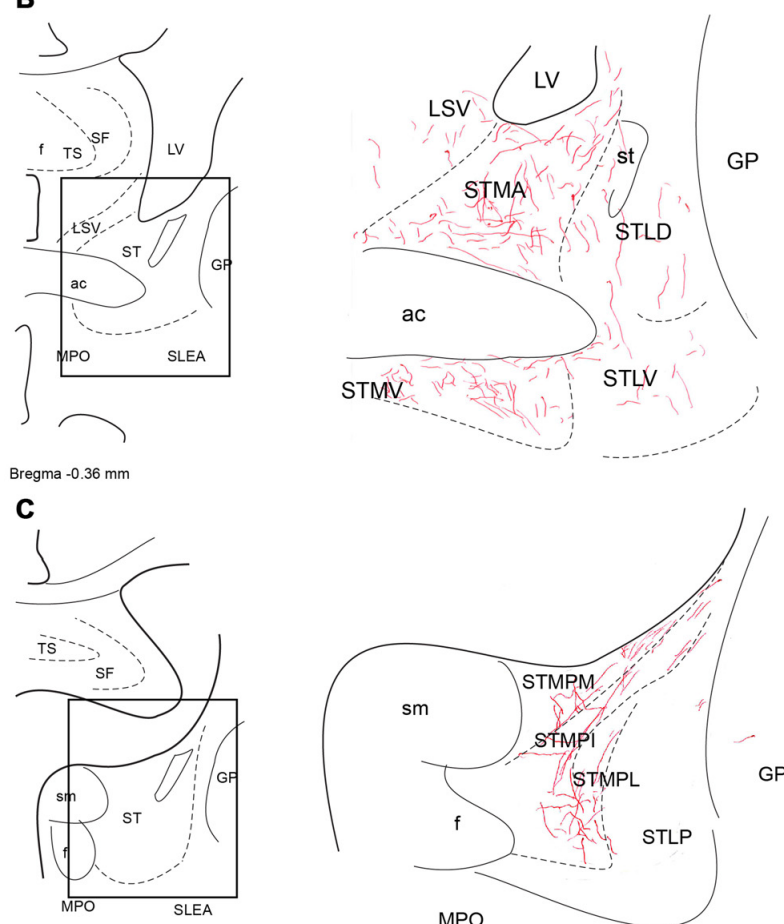

Bregma $-0.72 \mathrm{~mm}$

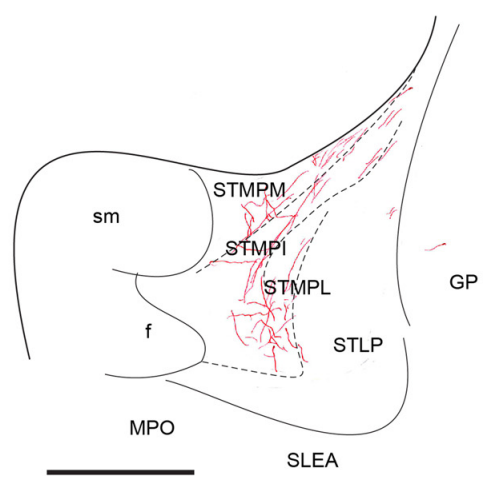

FIGURE 3 | Distribution of anterograde fiber labeling in the bed nuclei of the stria terminalis (ST) after a BDA injection into the NI. Labeled fibers mainly occurred in the medial nuclei. (A-C) Represents the levels that are shown in a camera lucida detail of the corresponding bregma levels. Calibration bar $250 \mu \mathrm{m}$.

them from the La and the BMA/BMP. A dense concentration of $\mathrm{PV}$-positive neurons occurred in the $\mathrm{CxA}$ and in the BLV (Figure 5A). PV cells were abundant in the PLCo (Figures 5B-F). At some levels, PV-positive neurons appeared at the boundary between the La and the BL nuclei (Figure 5E). There were also abundant PV neurons in the AHi (Figure 5F), whereas PV neurons were absent from the medial and central nuclei.

CB-28kD-positive neurons followed a similar pattern, but some CB-28kD neurons were also observed in amygdala areas of subcortical-subpallial origin. This was especially evident in the 


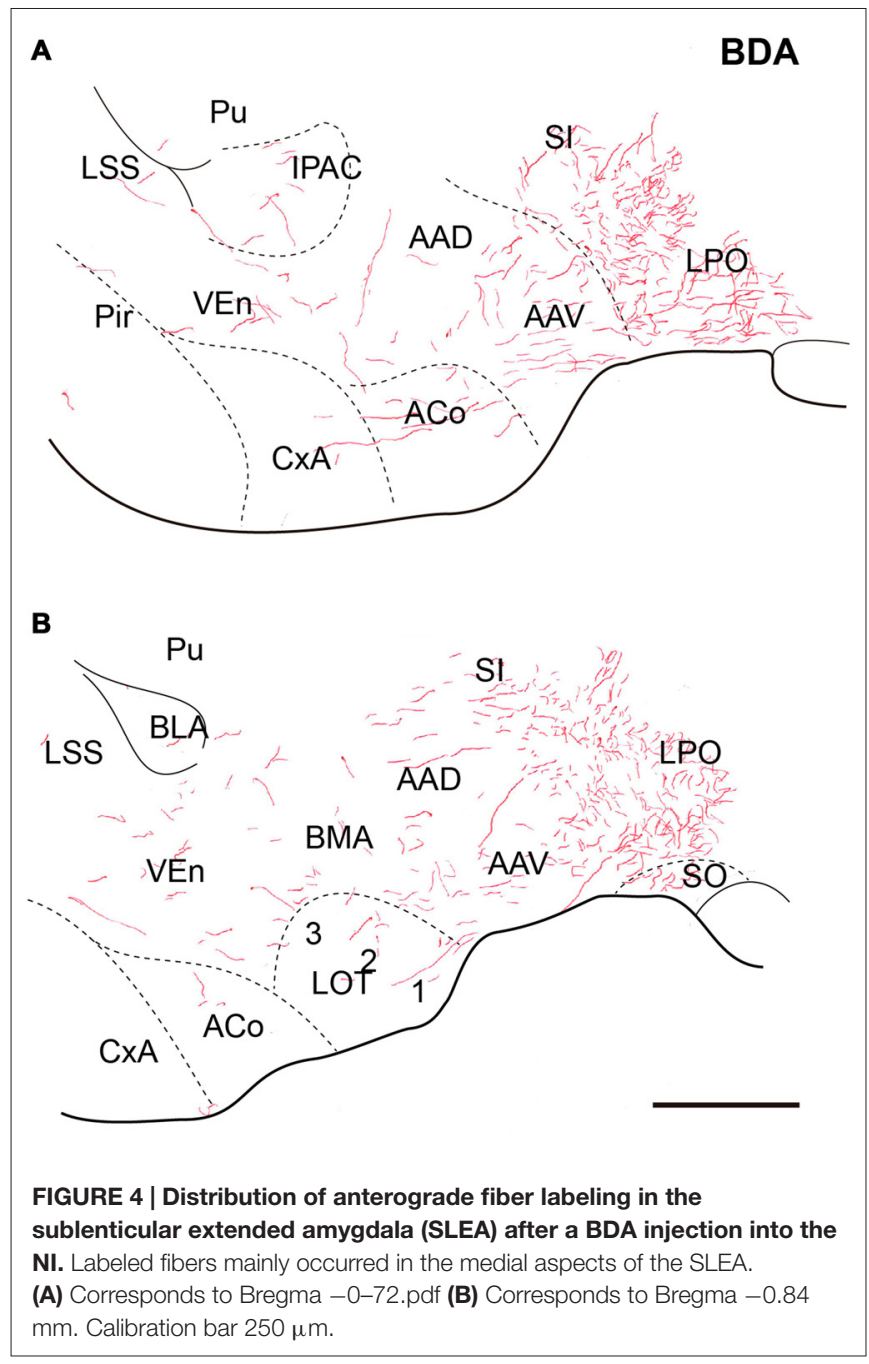

MeAD and MeAV vs. MePD and MePV. Thus, the occurrence of CB28kD-positive neurons is a specific feature of the anterior nuclei of the medial amygdala (Figure 6A). At more caudal levels, CB28kD neurons were concentrated in the cortical nuclei, including the PLCo and the PMCo (Figures 6C-F).

$\mathrm{CR}$ immunoreactivity was present in an intense band in the superficial layer of the cortical and medial amygdala nuclei. $\mathrm{CR}$-positive neurons were also present in the anterior nuclei of the medial amygdala (MeAD and MeAV; Figures 7A-C), but were scarce in the posterior nuclei (MePD and MePV). Only dispersed CR-positive cells were observed in the BMP and BMA (Figures 7B-E), while abundant CR-positive neurons were present in the AHi and in the PMCo (Figure 7F). At these caudal levels CR neurons were concentrated at the boundary between the ventromedial subnucleus of the lateral amygdala (LaVM) and BLP, an area that also contained dense plexuses of RLN3 fibers (Figure 7F).

At the most rostral level, dense plexuses of varicose relaxin3-positive fibers were observed penetrating the MeAD and MeAV of medial amygdala, originating from fiber tracts in the nearby medial forebrain bundle (Figures 5A, 6A, 7A), which then dispersed within more anterior levels giving rise to dispersed labeling in the $\mathrm{AD}$ and $\mathrm{AV}$ nuclei and extending to the SLEA. Sparse relaxin-3-positive fibers were also observed innervating the intercalated nuclei surrounding the lateral and basal nuclei, whereas the central nucleus was devoid of immunoreactivity (Figures 5A-C, 6A-C, 7A-C). Dense plexuses of relaxin-3 varicose fibers were observed in DEn and VEn. A moderate relaxin-3 innervation was also observed in a region between the cortical and the basolateral amygdala that corresponded to the basomedial nuclei (Figures 5A,B).

At progressively more caudal levels (Figures 5C,D, 6C,D, 7C,D), the densest relaxin-3 innervation was observed in the anterodorsal (ADMeA) and anteroventral (AVMeA) medial amygdala nuclei. Dense immunoreactivity was also observed in the STIA (Figures 5D,E, 6D,E, 7D,E). Labeling was sparse in the olfactory amygdala and piriform cortex, basal, lateral and central amygdala, and dispersed fibers were observed associated with intercalated cell groups lying between the basolateral and basomedial amygdala nuclei.

At caudal levels, the relaxin-3 innervation was concentrated in inner amygdala nuclei comprising the posteromedial cortical area (PMCo), the AHi and the posterior basomedial nucleus (BMP). A band of intense labeling was also observed at the boundary between the lateral (LaVM) and posterior basolateral nuclei BLP (Figures 5F, 6F, 7F).

\section{Relaxin-3 Innervation of the Bed Nucleus of the Stria Terminalis (ST)}

ST nuclei were well delineated by CB-28kD and CR immunoreactivity and relaxin-3 inputs were primarily confined to the medial aspects of the ST (Figure 8). At the most rostral levels of ST (Figures 8A,D), dense CB-28kD-positive neurons were observed in the lateral nuclei comprising the laterodorsal (STLD) and lateral juxtacapsular nuclei (STLJ), which contained dispersed relaxin-3-positive fibers (Figure 8A). In contrast, CR neurons were abundant in the medial anterior nucleus (STMA), which contained moderate levels of relaxin-3-positive fibers that coursed around the anterior horn of the anterior commissure (Figure $8 \mathbf{B}$ ). Relaxin-3 inputs were also observed in nuclei adjacent to the anterior commissure bundles, namely the ventral medial nucleus (STMV), whilst the ventral aspects of the lateral nucleus (STLV) contained sparse relaxin-3-positive fibers (Figures 8A,B).

At mid-levels of the ST (Figures 8B,E), few relaxin-3-positive fibers were observed in the medial regions, which comprised both the anterior (STMA) and ventral (STMV) divisions that were clearly identified by a dense cluster of CR-positive neurons (Figure 8D). In contrast, dispersed fibers were observed in the lateral nuclei (STLD, STLP and STLJ), and parastriatal (PS) and funicular $(\mathrm{Fu})$ nuclei.

At caudal levels (Figures 8C,F), relaxin-3-immunoreactive fibers were concentrated in all medial nuclei, comprising the posteromedial (STMPM), posterointermediate (STMPI) and posterolateral (STMPL) divisions, and at this level, some relaxin3 -positive fibers were also found in the posterior division of 


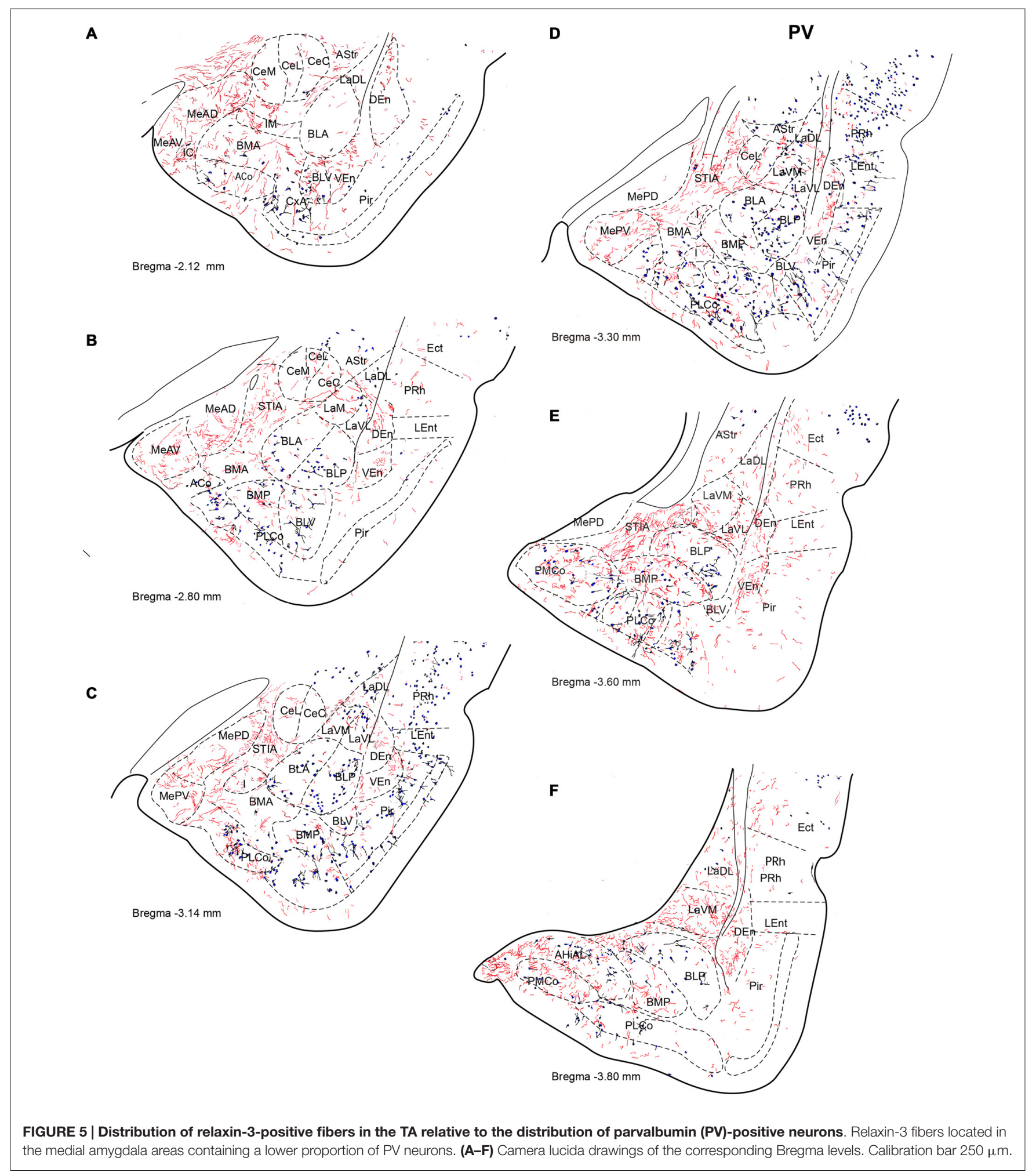

the lateral nucleus (STLP). At caudal and ventral levels of the ST, relaxin-3 fibers appeared to be in continuity ventrally with labeled fibers coming from the rostral and dorsal aspects of the SLEA (Figures 8C,F).

\section{Relaxin-3 Innervation of the Bed Nucleus of the Sublenticular Extended Amygdala (SLEA)}

Relaxin-3-positive fibers were sparse in this rostral extension of the amygdala. At the coronal level of the rostral amygdala, 


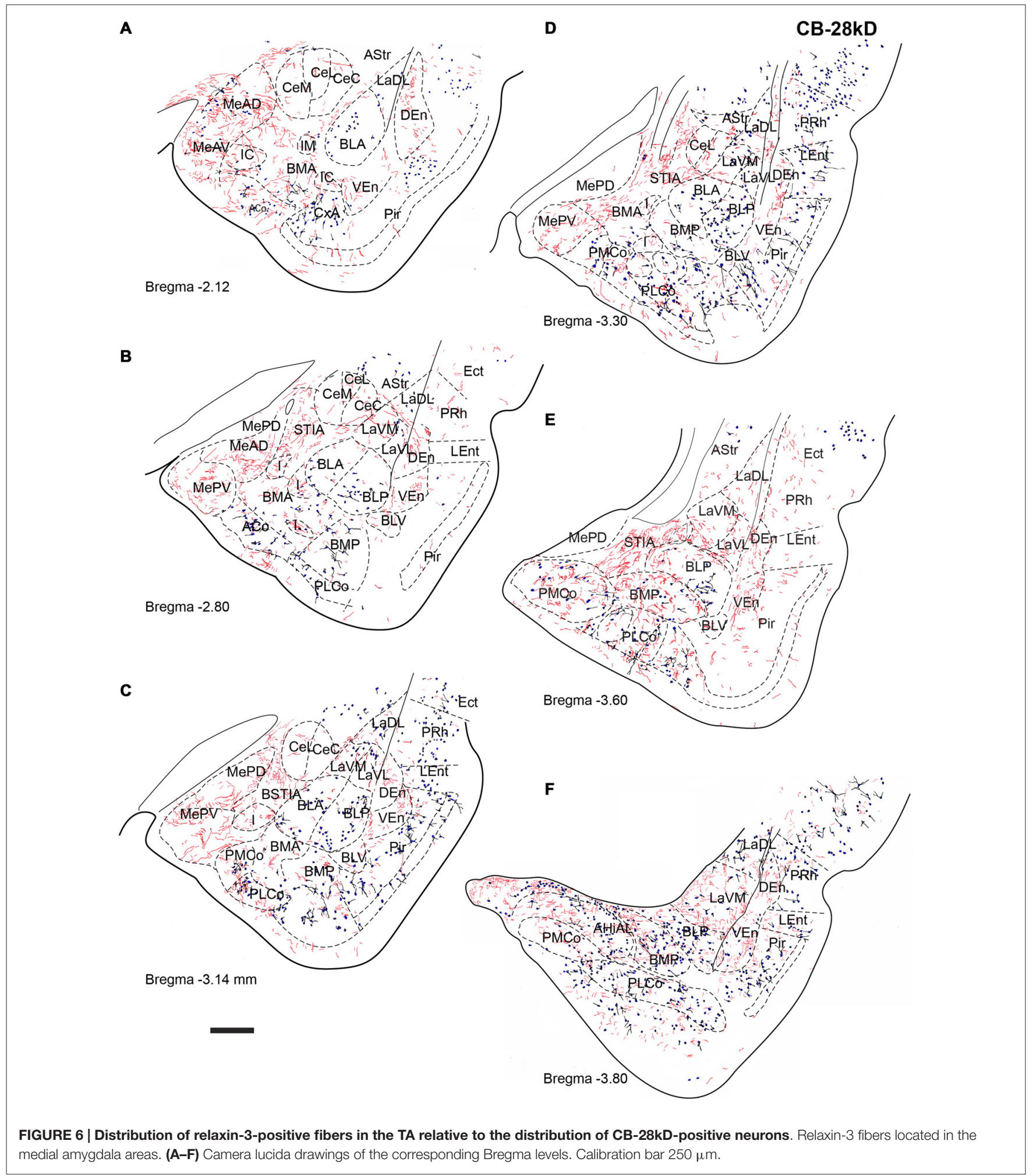

relaxin-3-labeled fibers were most concentrated in the horizontal diagonal band (HDB) and in the magnocellular preoptic nucleus (MPO; Figures 9A,C). From this region, some fibers coursed dorsally into the substantia innominata and laterally forming a band in the anterior amygdala area located between the ventral pallidum and the olfactory tubercle, which contained CB-28kD-positive neurons (Figure 9A), but was devoid of CR-positive cells (Figure 9C). Relaxin-3-labeled fibers were 


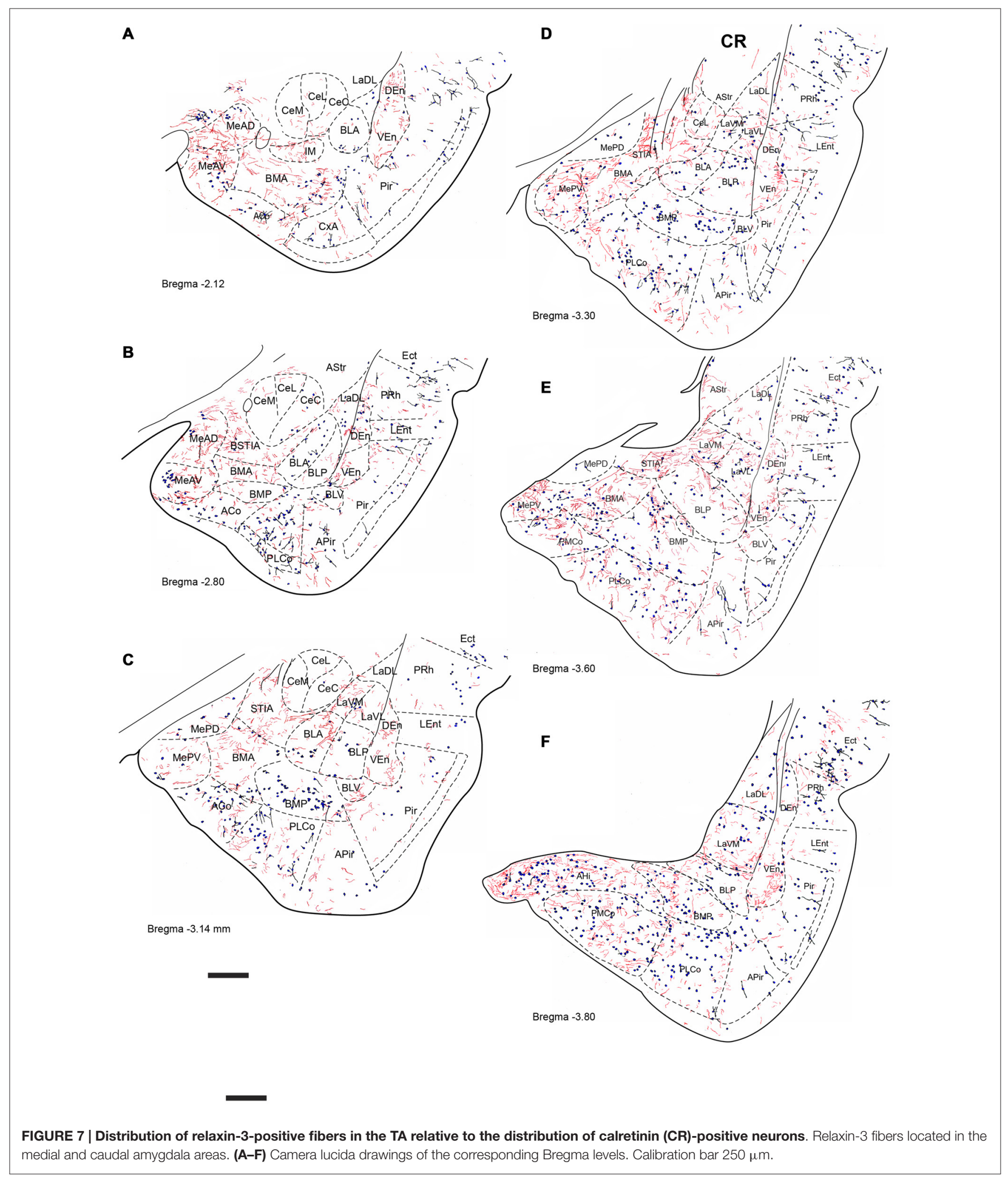

also observed in the VEn and in the medial division of the IPAC, whereas the ventral pallidum lacked relaxin3-immunoreactivity.
At more caudal levels of the SLEA (Figures 9B,D), a dense plexus of relaxin-3-immunoreactive fibers was observed in the LPO. These fibers extended laterally to the ventral (AAV) and 
A

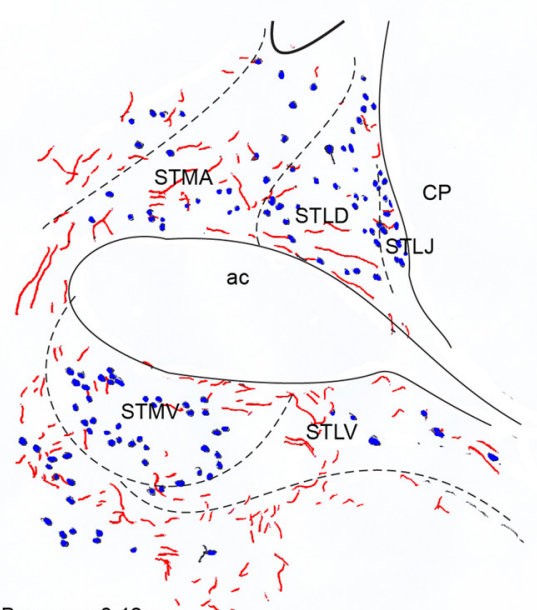

Bregma $+0.12 \mathrm{~mm}$

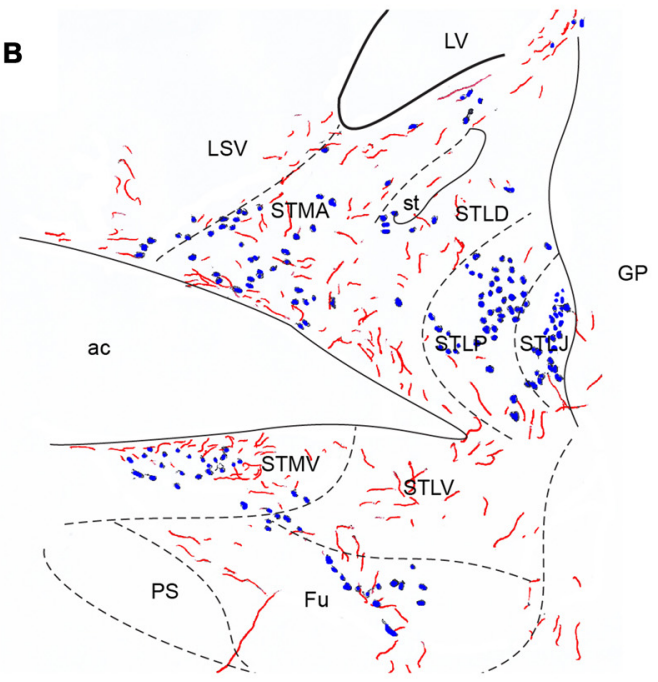

Bregma $-0.36 \mathrm{~mm}$

C

Bregma $-0.72 \mathrm{~mm}$
D

CR

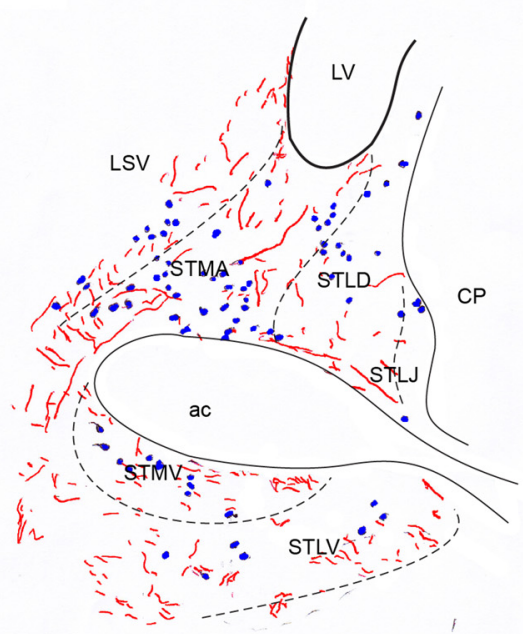

E

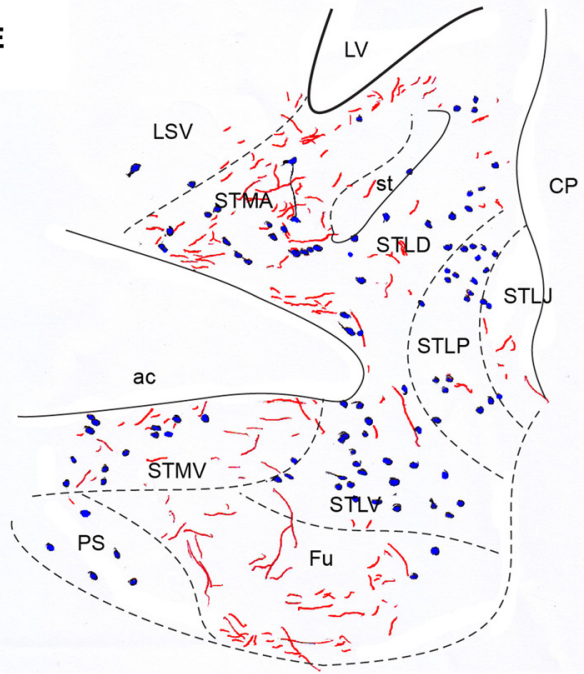

$\mathbf{F}$

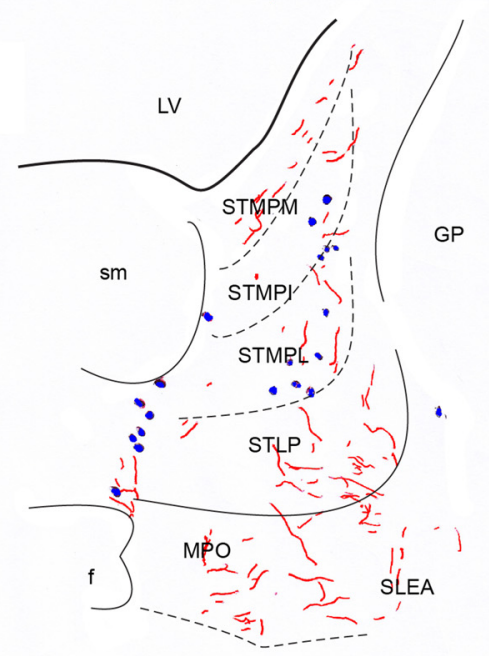

FIGURE 8 | Distribution of relaxin-3-positive fibers in the nuclei of the ST relative to the distribution of CB-28kD-positive neurons (A,C,E) and CR-positive neurons (B,D,F). Calibration bar $250 \mu \mathrm{m}$. 

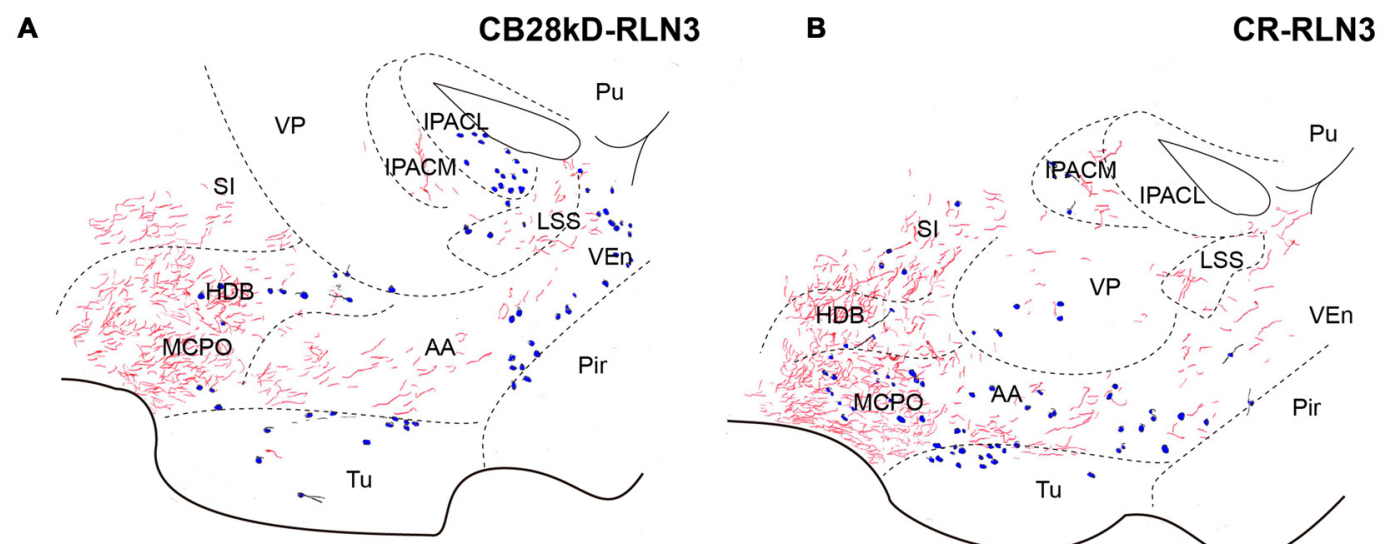

C

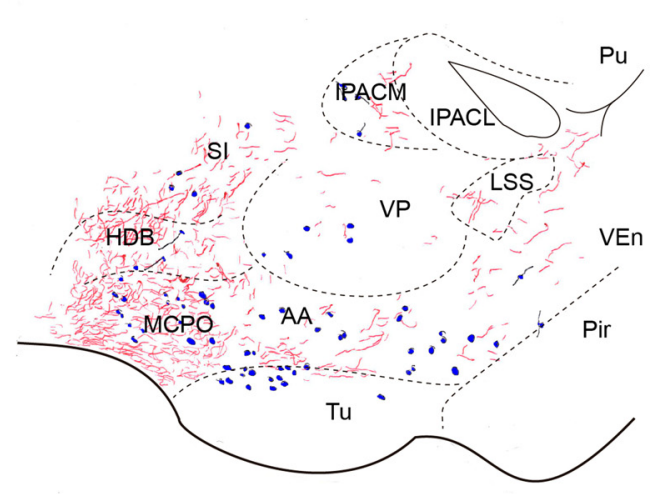

D

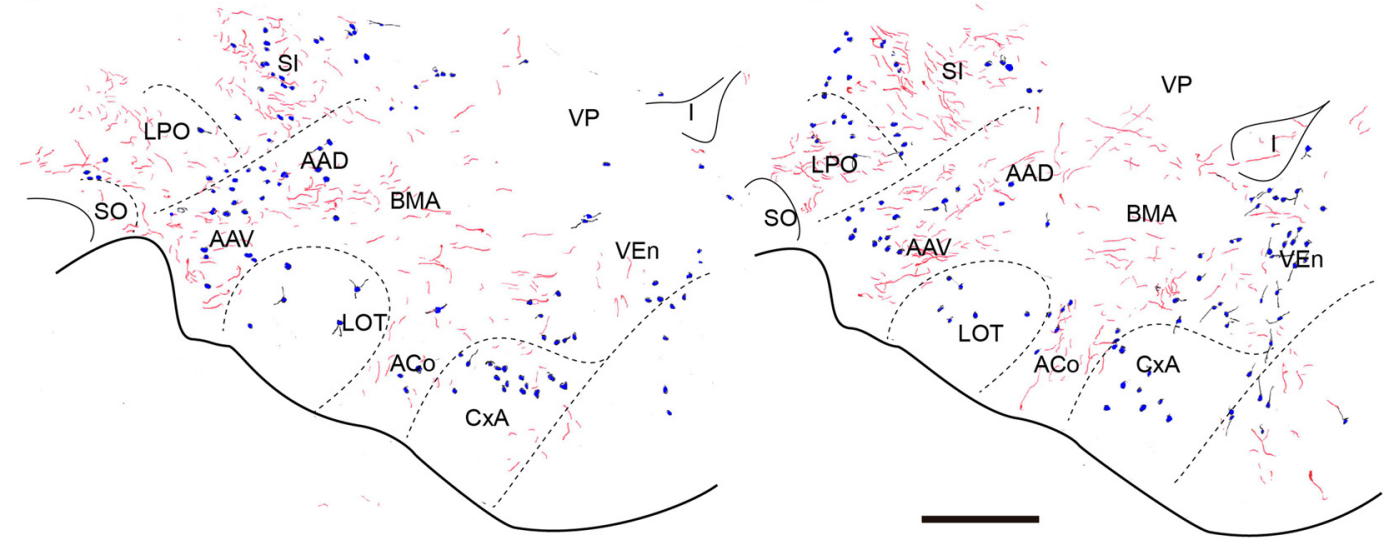

FIGURE 9 | Distribution of relaxin-3-positive fibers in the SLEA relative to the distribution of CB28kD-positive neurons (A,C) and CR-positive neurons (B,D). Calibration bar $250 \mu \mathrm{m}$.

dorsal (AAD) divisions of the anterior amygdala and dorsally to the substantia innominata (Figures 9B,D). Sparse fibers were also observed in the DEn and VEn. The interstitial nucleus of the posterior arm of the anterior commissure contained two divisions, the medial (IPACM) and the lateral (IPACL). While the IPACM contained a dense plexus of relaxin-3 fibers, the IPACL was devoid of fibers, but contained a population of CB28kD-positive neurons (Figures 9A-C). The ventral pallidum, nucleus of the lateral olfactory tract (LOT) and the bed nucleus of the accessory olfactory tract (BAOT) were devoid of relaxin-3 immunoreactivity (Figures 9B,D).

\section{Distribution of mR-Positive NI and Relaxin-3-Positive Inputs and Calcium-Binding Protein-Positive Neurons in the Amygdala}

Close appositions were observed between anterogradely-labeled fibers positive for $\mathrm{mR}$ and $\mathrm{PV}$ soma and processes in the ventrolateral division of the lateral amygdala (Figures 10A,B). In permanent $\mathrm{DAB}$ stained samples, it was also possible to find close contacts of $\mathrm{mR}$ positive fibers and $\mathrm{CR}$ processes in the AHi (Figures 10C,D). Confocal images from different amygdala nuclei revealed a graded pattern of contacts between relaxin-3-positive fibers and calcium binding protein somata and processes. These contacts were evident in the $\mathrm{La}$ and $\mathrm{BL}$ divisions and in some cases the contacts occurred between fibers and processes outside the boundaries of the nucleus (Figures 10E-G). In the PLCo relaxin-3 fibers were found surrounding the neuronal somata of CB-28kD-positive neurons (Figures $11 \mathbf{A}-\mathrm{C}$ ). Also relaxin3 fibers contacted somata of $\mathrm{CB}-28 \mathrm{kD}$ neurons in the lateral nucleus (Figures 11D-F). CR neurons of the medial amygdala also received contacts from relaxin-3-positive fibers (Figures 11G-I). Finally, contacts were also observed in the medial nucleus of the ST where relaxin-3 fibers contacted processes (Figures 11J-L).

\section{Co-Localization of Relaxin-3 and Synaptophysin}

Synaptophysin (Syn) immunofluorescent staining was used to confirm the presence of relaxin-3 synapses/terminations on amygdala neurons. These studies resulted in granular labeling surrounding neuronal soma, which appear as immuno-negative "dark holes". Syn boutons were clearly observed in the first 5-10 $\mu \mathrm{m}$ below the section surface and within this region Syn 

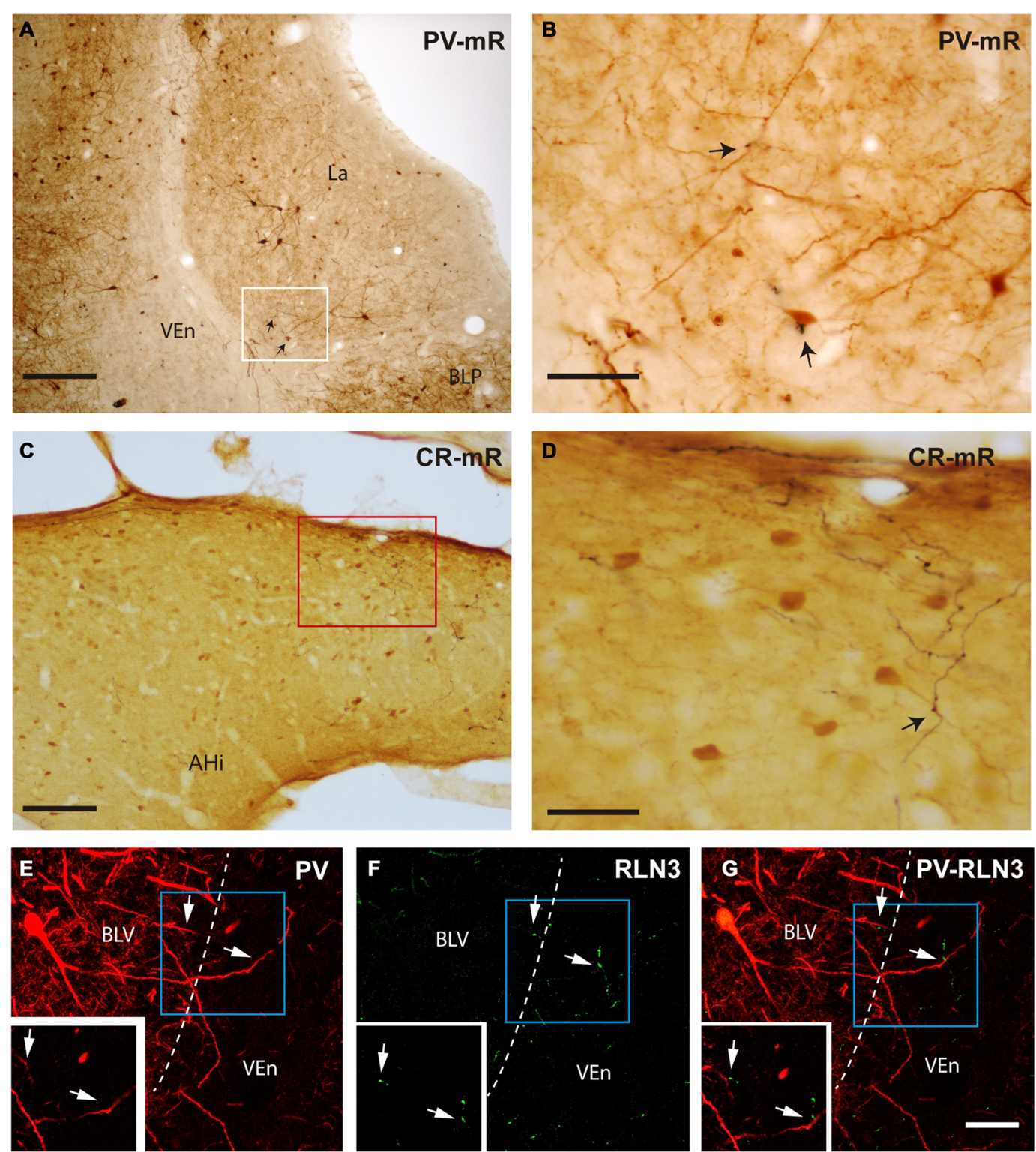

FIGURE 10 | Close apposition between mR anterogradely-labeled NI fibers or relaxin-3-positive fibers and PV-positive or CR-positive neurons. (A) Posterior lateral amygdala region (containing mR-positive elements and neurons stained for PV (case sf2). (B) Higher magnification of the area labeled in (A) representing a close contact between an anterogradely labeled fiber (black) and the soma of a PV-positive neuron. (C) Anterograde labeling was abundant in the caudal aspects of the amygdala, particularly in the amygdalohippocampal transition area. (D) Some of the anterogradely-labeled elements contacted CR neuron processes (arrow; case sf3). (E-G) Confocal images illustrating contacts between relaxin-3 fibers and PV dendrites in the basolateral ventral nucleus (BLV). The main images represent the maximal projection and the insets a single $0.3 \mu \mathrm{m}$ stack. Some dendrites of these neurons extend beyond the boundaries of the nucleus, in this case in the ventral endopiriform nucleus (VEn) which contained dense relaxin-3 labeling. Calibration bars, $200 \mu \mathrm{m}$ (A), $20 \mu \mathrm{m}$ (B), $100 \mu \mathrm{m}$ (C), $40 \mu \mathrm{m}$ (D), $30 \mu \mathrm{m}$ (E-G)

immunofluorescent boutons averaged $400 \mathrm{~nm}$ in diameter. Clear colocalization of Syn with relaxin-3-immunoreactive boutons was observed in the medial nucleus of the ST (Figures 12A-C), DEn (Figures 12D-F), MeAD (Figures 12G-I) and MePV (Figures 12J-L). In order to undertake a quantitative estimation of the occurrence of double labeling (Syn/relaxin-3) in the amygdala, tracks of fibers were measured and the number of Syn boutons associated with the fiber was quantified (Table 3).
On average between 5-30\% of relaxin-3 fibers did not contain any Syn labeling. For the remaining relaxin-3 positive fibers, Syn boutons occurred in $0.1-2$ boutons per $10 \mu \mathrm{m}$ of relaxin- 3 fiber.

\section{DISCUSSION}

Using the anterograde tracers, $\mathrm{mR}$ and $\mathrm{BDA}$, we observed a NI projection to specific regions in the amygdala including the 

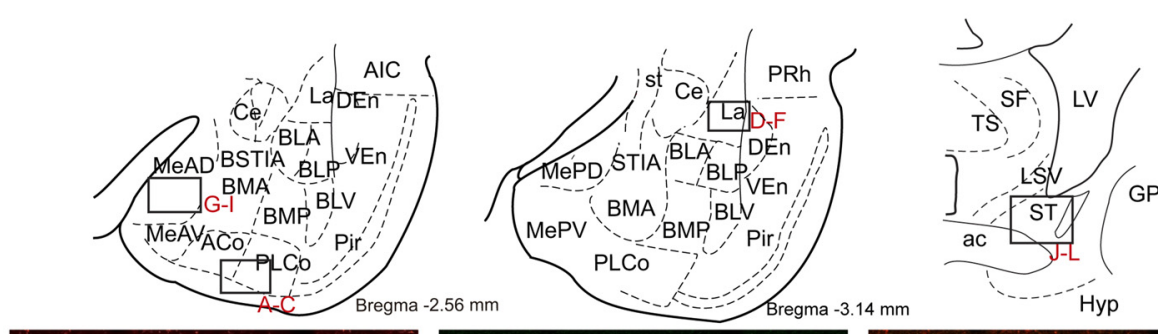
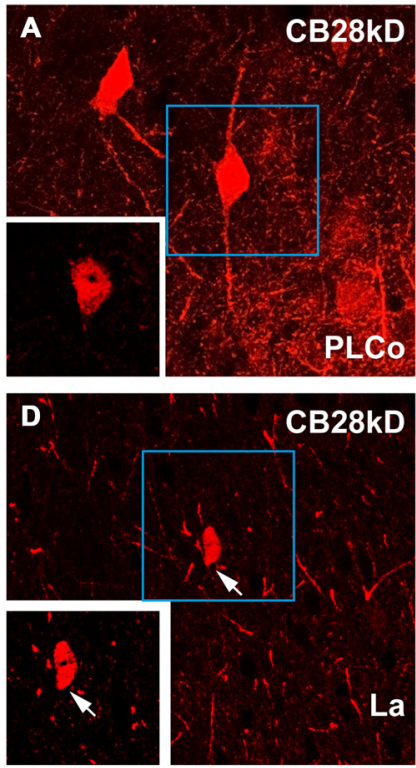

CB28kD
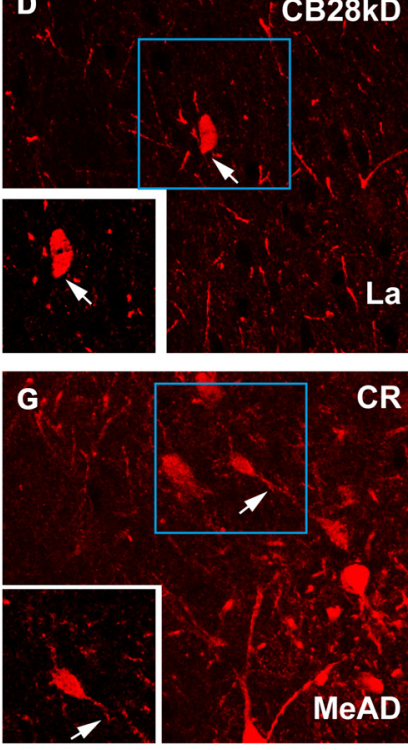

CR

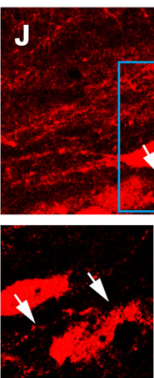

CR
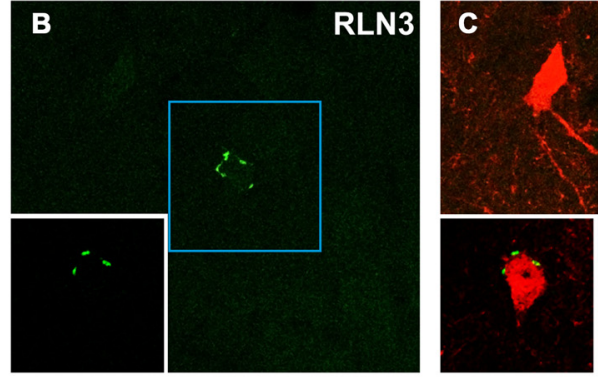

CB28kD-RLN3
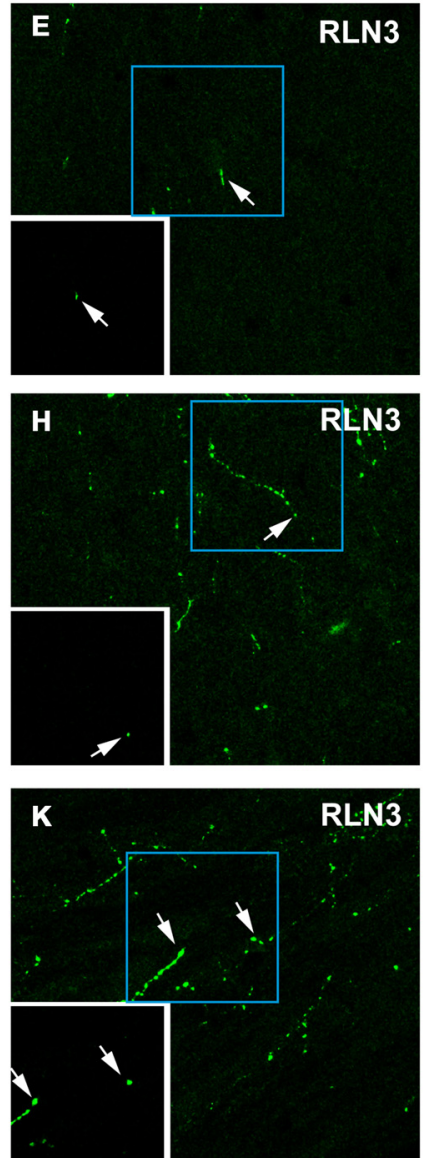
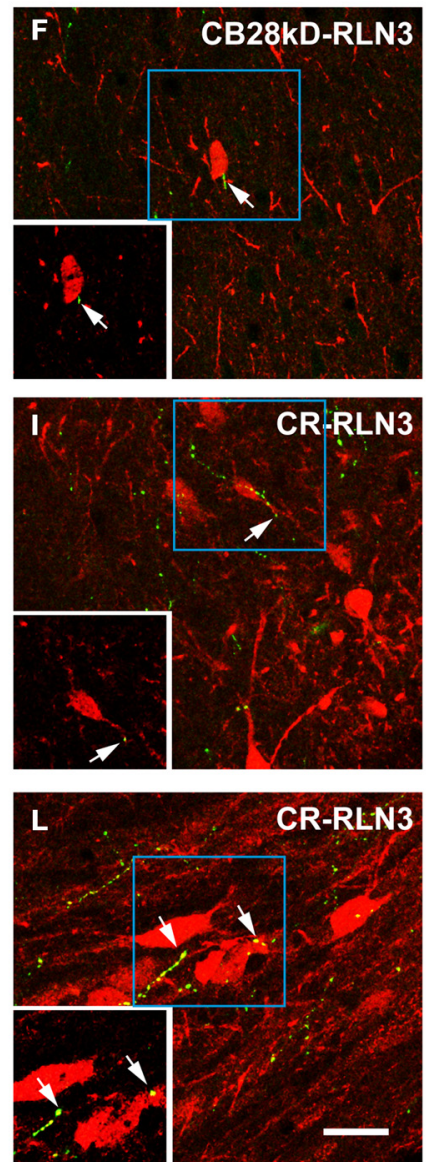

FIGURE 11 | Confocal images of close apposition between calcium binding positive neurons and processes and relaxin-3 positive fibers. Large images correspond to a maximal projection of stacks of 20 images of scans of $0.3 \mu \mathrm{m}$. Insets illustrate a single $0.3 \mu \mathrm{m}$ section illustrating the contact. (A-C) Contact between a relaxin-3 fiber and a CB28kD somata in PLCo. (D-F) Contact of a relaxin-3 fiber with a CB28kD fiber in the La. (G-I) Contacts between RLN3 fibers and CR positive somata and processes in the MeAD. (J-L) Contacts between RLN3 fibers and CR somata and processes in the STM. Calibration bar $20 \mu m$.

nuclei of the ST and the SLEA. NI fibers extend throughout the medial nuclei of the ST, medial aspects of the SLEA, and in the TA extend throughout the medial amygdala. Dispersed fibers were also located in a broad band along the basomedial nuclei. This pattern agrees with the general distribution of relaxin-3 fibers which are present within the medial ST and 

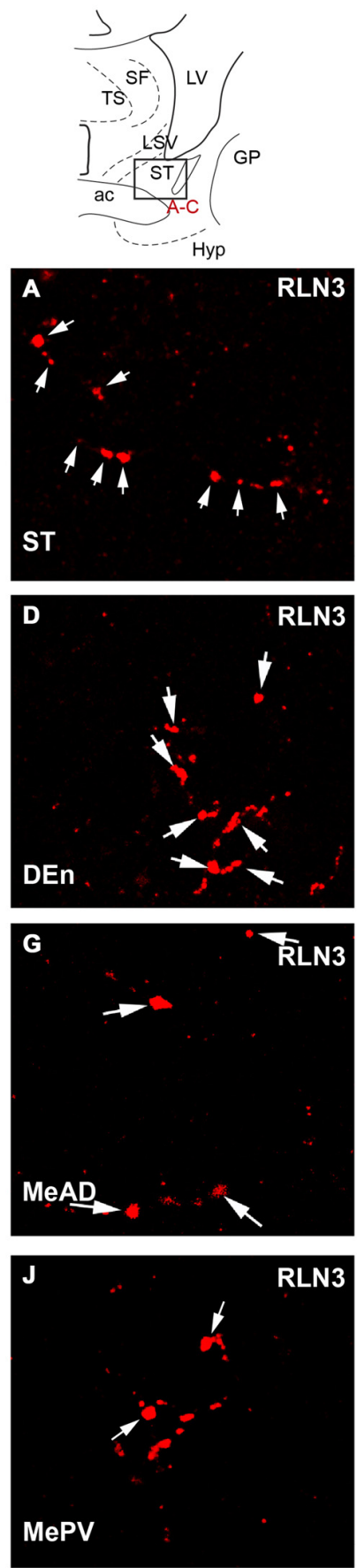
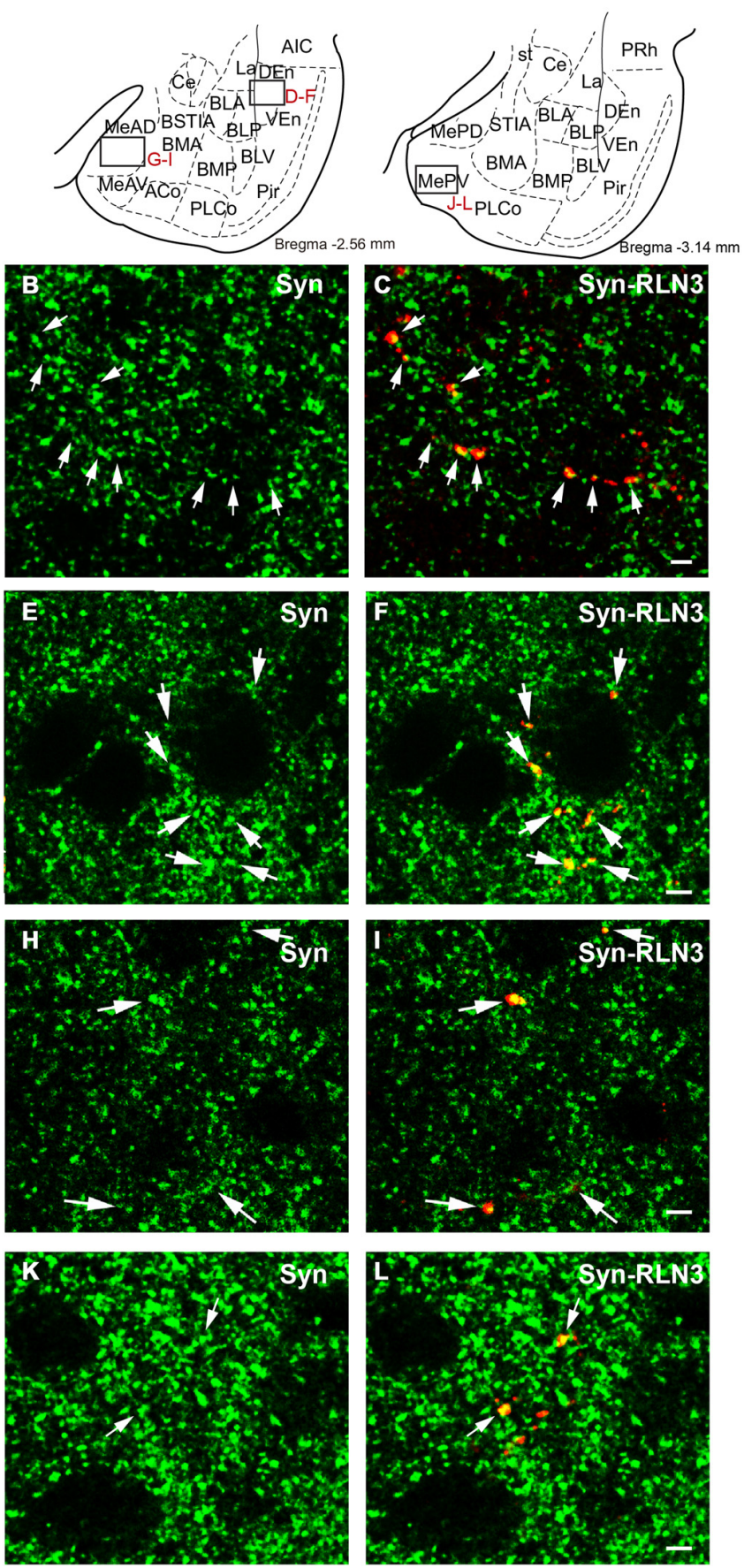

FIGURE 12 | Confocal images revealing the colocalization of relaxin-3 (red) and synaptophysin (green) in the framed areas of uppermost schematic images. Single $0.5 \mu \mathrm{m}$ sections displaying the localization (arrows) of relaxin-3 (A) synaptophysin (B) and a merged image (C) in the medial aspect of the ST. Single $0.5 \mu \mathrm{m}$ sections displaying the localization (arrows) of relaxin-3 (D) synaptophysin (E) and a merged image (F) in the endopiriform nucleus. Single $0.5 \mu \mathrm{m}$ section displaying localization (arrows) of relaxin-3 (G) synaptophysin (H) and a merged image (I) in the medial amygdala (anterior dorsal nucleus). Single $0.5 \mu \mathrm{m}$ section displaying the localization (arrows) of relaxin-3 (J) synaptophysin (K) and a merged image (L) in the medial amygdala (posterior ventral nucleus). Calibration bars $5 \mu \mathrm{m}$.

SLEA, the medial amygdala, and in a broad band covering the basomedial nuclei. In addition, groups of anterograde and relaxin-3 fibers invaded specific centers like the caudal VMLa. This suggests that a significant population of relaxin-3 fibers targeting the amygdala arise from the NI, although, a contribution of relaxin-3 fibers from relaxin-3 producing neurons in other areas, namely the pontine raphe nucleus, ventral periaqueductal gray and/or the area dorsal to the lateral 
TABLE 3 | Quantitative estimation of the colocalization of synaptophysin (syn) and relaxin-3 in the different nuclei of the amygdala.

\begin{tabular}{lcc}
\hline $\begin{array}{l}\text { Amygdala } \\
\text { nucleus }\end{array}$ & $\begin{array}{c}\text { \% of RLN3 fibers without } \\
\text { colocalization with Syn } \\
\text { botons mean } \pm \text { SEM }\end{array}$ & $\begin{array}{c}\text { Average number of Syn } \\
\text { boutons per } \mathbf{1 0} \boldsymbol{\mu ~ \mathbf { m }} \\
\text { of RLN3 fiber } \pm \text { SEM }\end{array}$ \\
\hline SLEA & $45.1 \pm 3.1$ & $0.61 \pm 0.15$ \\
CeA & $18.3 \pm 2.3$ & $1.05 \pm 0.34$ \\
MeA & $21.4 \pm 9.0$ & $1.97 \pm 0.26$ \\
La & $10.8 \pm 2.4$ & $4.94 \pm 3.30$ \\
BL & $29.2 \pm 5.9$ & $2.05 \pm 0.62$ \\
BM & $17.4 \pm 7.0$ & $2.16 \pm 1.37$ \\
ST & $27.8 \pm 7.9$ & $0.14 \pm 0.32$ \\
Cortical & $16.1 \pm 8.6$ & $2.04 \pm 1.15$ \\
\hline
\end{tabular}

substantia nigra (Tanaka et al., 2005; Ma et al., 2007), cannot be ruled out.

According to our data, there is a dense concentration of relaxin-3 fibers in the medial amygdala which also contains a high concentration of RXFP3 receptors. In contrast, the central nucleus that also contains a high concentration of RXFP3 (Ma et al., 2007; Smith et al., 2010; Lenglos et al., 2014) is largely devoid of relaxin-3. In the same way, while we have observed a high concentration of relaxin-3 fibers in the medial ST, RXFP3 receptors are concentrated in the lateral ST. Thus, while in the medial amygdala, fibers and receptors occupy the same location, there is a mismatch in the distributions in the central nucleus and the nuclei of the ST. A mismatch between fibers and the distribution of postsynaptic receptors has been described for the amygdala opioid system (Agnati et al., 1986) and volume transmission, whereby peptides can be delivered into extrasynaptic spaces and diffuse for a long distance (ThuresonKlein et al., 1986; Zhu et al., 1986) is a possible form of neural communication in the amygdala. Although relaxin-3 is present in synapses in the thalamus (Tanaka et al., 2005) and in the medial septum (Olucha-Bordonau et al., 2012), a matchmismatch between fibers and receptors has also been described for the cholecystokinin (CCK) transmission system. CCK fibers innervate the lateral central nucleus of the amygdala, which does not display $\mathrm{CCK}_{2}$ receptors, and the intercalated nuclei, which express $\mathrm{CCK}_{2}$ receptors, whereas the basolateral amygdala does not contain fibers but is rich in $\mathrm{CCK}_{2}$ receptors (Pérez de la Mora et al., 2007). CCK delivered in the central amygdala of rodents in the absence of danger is thought to activate $\mathrm{CCK}_{2}$ receptors of the basolateral amygdala and depolarize these neurons, leading to a maintained basal level of arousal (Pérez de la Mora et al., 2008). Thus, volume transmission is particularly adapted to neuropeptide neurotransmission signaling (Pérez de la Mora et al., 2007), as there are no peptide re-uptake mechanisms and inactivation of peptides strongly depends on extracellular peptidases, which limit their diffusion through the extracellular space (Davis and Konings, 1993), as reported for substance P in the spinal cord (Duggan et al., 1990, 1992). In this regard, relaxin3 can be slowly degraded by the insulin degrading enzyme (Bennett et al., 2009) which is also expressed in the brain (Kuo et al., 1993).

In addition to the medial extended amygdala, relaxin-3 and NI-anterogradely labeled fibers were observed in central extended amygdala and in the lateral, basolateral and basomedial nuclei. It is well documented that amongst the lateral basal and central nuclei, sensory information is conveyed from the lateral to the central nucleus (Pitkänen et al., 1997), a process important for emotional processing and fear conditioning (Amorapanth et al., 2000; Nader et al., 2001). In this regard, we have demonstrated that electrolytic lesions of the NI impair within session extinction of fear conditioning (Pereira et al., 2013). Thus, putative relaxin- 3 projections from the NI to the medial and ventrolateral aspects of the lateral amygdala and to the basolateral and basomedial nuclei could subserve a modulation of the extinction process by activation of RXFP3 within these areas and/or in the adjacent CeA.

Anatomical and functional comparisons reveal parallels between the central relaxin-3 and neuropeptide S (NPS) systems. NPS is expressed in neurons located in only a few brain areas-including in the pericoerulear area, in the KöllikerFuse nucleus, and in a small number of neurons within the dorsomedial hypothalamic nucleus (Xu et al., 2004; Pape et al., 2010; Clark et al., 2011), a similar distribution to that in humans (Adori et al., 2015). A major target of the NPS system is the endopiriform nucleus, which is also densely targeted by relaxin-3 fibers. NPS infusion into the endopiriform nucleus induced an increase in glutamatergic excitation assessed in ex vivo preparations that, in turn, resulted in a general decrease in GABAergic inhibition in the basal and lateral amygdala and an enhancement of spike activity in these nuclei. In a parallel fashion, infusion of NPS in this nucleus results in a reduction of freezing in contextual but not cued fear conditioning (Meis et al., 2008).

In the present studies, we have identified and detailed direct inputs of NI and relaxin-3 fibers to neurons expressing the calcium-binding proteins $\mathrm{PV}, \mathrm{CB}-28 \mathrm{kD}$ and CR. Putative contacts have been demonstrated in the lateral and basal amygdala nuclei and were clearly evident at the border between $\mathrm{LaVM}$ and $\mathrm{BLP}$, in the CeA, and in the AHi transition area. Specific types of inhibitory neurons characterized by their expression of particular calcium-binding proteins, have been shown to play a central role in fear processing (Ehrlich et al., 2009). For example, PV neurons of the basolateral nucleus differentially fire in association with an auditory cue or after footshock, suggesting they constitute, along with amygdaloid principal neurons, a dynamic disinhibitory microcircuit (Wolff et al., 2014).

PV neurons are also known to inhibit principal neurons of the lateral amygdala during noxious or salient stimuli (Chu et al., 2012; Bienvenu et al., 2015). In the current study, contacts between anterogradely-labeled NI fibers and PV neurons were observed in the lateral amygdala, suggesting a possible action on interneurons influencing the pathway from the lateral nucleus via the basal nucleus and finally targeting the central nucleus, thus providing a modulatory capability for altering fear acquisition and extinction. We also observed that the intercalated nuclei contain relaxin-3 fibers and these nuclei that surround the lateral nucleus receive direct projections from the prefrontal cortex which mediate the suppression of fear responses during the extinction process (Quirk et al., 2003; Paré et al., 2004). Thus, 
NI relaxin-3 projections to the intercalated nuclei may contribute to the modulation of the neural processes of fear extinction (Pereira et al., 2013) and further investigations are warranted, particularly in light of related functional impacts of relaxin3/RXFP3 signaling in related circuits.

In this respect, there is growing evidence that the NI plays an important role in modulating arousal and cortical activation via actions on the septohippocampal system and changes in hippocampal theta rhythm $(4-12 \mathrm{~Hz}$ oscillations detectable in the EEG; Brown and McKenna, 2015; Orzeł-Gryglewska et al., 2015). NI stimulation was initially demonstrated to increase hippocampal theta power and in contrast, NI lesion significantly attenuated hippocampal theta activity induced by stimulation of the reticularis pontis oralis (Nuñez et al., 2006). Similarly, increased hippocampal theta power was observed after infusion of an RXFP3-specific agonist into the septum, and infusion of an RXFP3-specific antagonist in the septum dosedependently attenuated hippocampal theta power and spatial working memory in rats (Ma et al., 2009). Furthermore, we have reported a differential effect of corticotrophin-releasing hormone $(\mathrm{CRH})$ on NI-relaxin-3 neurons in urethane-anesthetized rats, whereby NI-relaxin-3 neurons exhibited spontaneous firing that was phase-locked with hippocampal theta oscillations, whereas non-relaxin-3 neurons did not (Ma et al., 2013). Similarly, fear processing is related to changes in theta rhythm. During retrieval of fear memories, the amygdala and hippocampus display phase-locked activity at theta frequency (Paré et al., 2002; Seidenbecher et al., 2003). More recently, unit recordings from the infralimbic prefrontal cortex, the hippocampus CA1 and the lateral amygdala revealed that the pattern of theta oscillations correlated with individual behavioral responses during fear acquisition, retrieval and extinction (Lesting et al., 2011, 2013). Synchronization of theta oscillations between hippocampus and amygdala could in part depend on a common projection from the NI.

Central $\mathrm{CRH}$ infusion has been demonstrated to activate NI neurons expressing CRH-R1 (Bittencourt and Sawchenko, 2000; Van Pett et al., 2000), and stress activated neurons in the NI express relaxin-3 (Tanaka et al., 2005; Banerjee et al., 2010). Central infusion of an RXFP3 agonist has been found to have anxiolytic effects in adult rats (Ryan et al., 2013a) and mice (Zhang et al., 2015). Thus, these effects of RXFP3 signaling on anxiety-related mechanisms may involve the amygdala, although further studies are required in rat and mouse in appropriate models to further assess this possibility.

In addition to the putative function of relaxin-3/RXFP3 signaling in stress mechanisms, another function attributed to the NI relaxin-3 system is the modulation of feeding behavior. Intra-hypothalamic or icv infusion of relaxin-3 or RXFP3selective agonists results in promotion of feeding in satiated rats (McGowan et al., 2005, 2006; Haugaard-Kedström et al., 2011; Shabanpoor et al., 2012) and some effects on feeding behavior may occur via actions within the amygdala. Rats in which obesity was induced with a high fat diet and refeeding after food deprivation, displayed increased expression of RXFP3 in the central amygdala, as well as in the paraventricular hypothalamic nucleus, NI and nucleus of the olfactory tract, whereas such changes were not observed in rats in which a high fat diet did not induce obesity (Lenglos et al., 2014).

Finally, recent research has shown that central (icv) administration of an RXFP3 antagonist produced a dose-related decrease in self-administration of alcohol (Ryan et al., 2013b). This effect is in part mediated by effects within the extended amygdala, as bilateral infusion of an RXFP3 antagonist into the bed nucleus of the ST decreased self-administration of alcohol and stress-induced reinstatement of alcohol seeking (Ryan et al., 2013b). Thus the NI/relaxin-3 innervation of the medial divisions of the ST identified in the current study may provide the relaxin3 input involved.

In general, it appears that relaxin-3 positive fibers that can potentially release the peptide are present in the medial division of the amygdala and medial nuclei of the ST, while neurons which express RXFP3 mRNA are present in these areas, but are more concentrated in the central amygdala and the lateral nuclei of the ST. Indeed a mismatch between areas expressing peptide receptors and the location of fibers delivering peptide ligand is also observed with the $\mathrm{CRH}$ innervation of the amygdala. While the lateral central amygdala receives a dense innervation of CRH fibers (Swanson et al., 1983; Sakanaka et al., 1986, 1987); neurons expressing the CRH-R1 receptor are concentrated in the medial nucleus of the central amygdala (Van Pett et al., 2000). However, in transgenic mice expressing CRH-R1, the dendritic tree of CRH-R1 neurons may be in close contact with CRH fibers within surrounding areas (Justice et al., 2008). Therefore, at this stage, it is possible that synaptic, extrasynaptic or volume transmission mechanisms may be involved in peptidergic transmission within the medial and lateral divisions of the ST or within the medial and central nuclei of the amygdala.

In conclusion, we have documented the topographical projections from the NI to selective regions (nuclei/subnuclei) of the amygdala, including the medial and extended amygdala, the lateral and basal nuclei and the endopiriform nucleus, which may modulate various amygdala-driven functions, including feeding, social behavior, fear conditioning and extinction, and reward and motivation. Separate or collateral projections of NI neurons to the septum, hippocampus and amygdala may provide a neural network capable of rhythmic theta synchronization between the hippocampus and the amygdala during emotionally-related processes. The presence of relaxin-3 in a relevant population of these NI neurons and pharmacological studies with RXFP3selective peptides suggest that relaxin-3/RXFP3 signaling may contribute to these important physiological and behavioral modalities.

\section{AUTHOR CONTRIBUTIONS}

FNS and CWP performed double ICC and camera lucida drawings, AMS-P, performed double immunofluorescence, prepared figures and reported intellectual input, $\mathrm{MOG}$ performed double IF for Syn and CBP, SM and ALG provided intellectual input and discussed along the various versions, FEO-B performed tracing injections, double ICC and IF, wrote the first draft, corrected versions and prepared figures. 


\section{ACKNOWLEDGMENTS}

This research was supported by the following grants and awards: CAPES-Brasil Bex 4494/09-1 (FNS) and 4496/09-4 (CWP); Generalitat Valenciana AICO/2015/042; Universitat

\section{REFERENCES}

Adolphs, R. (2008). Fear, faces and the human amygdala. Curr. Opin. Neurobiol. 18, 166-172. doi: 10.1016/j.conb.2008.06.006

Adori, C., Barde, S., Bogdanovic, N., Uhlén, M., Reinscheid, R. R., Kovacs, G. G., et al. (2015). Neuropeptide $S$ - and Neuropeptide $S$ receptor-expressing neuron populations in the human pons. Front. Neuroanat. 9:126. doi: 10.3389/fnana. 2015.00126

Aggleton, J. P. (1993). The contribution of the amygdala to normal and abnormal emotional states. Trends Neurosci. 16, 328-333. doi: 10.1016/01662236(93)90110-8

Agnati, L. F., Fuxe, K., Zoli, M., Ozini, I., Toffano, G., and Ferraguti, F. (1986). A correlation analysis of the regional distribution of central enkephalin and beta-endorphin immunoreactive terminals and of opiate receptors in adult and old male rats. Evidence for the existence of two main types of communication in the central nervous. Acta Physiol. Scand. 128, 201-207. doi: 10.1111/j.17481716.1986.tb07967.x

Amorapanth, P., LeDoux, J. E., and Nader, K. (2000). Different lateral amygdala outputs mediate reactions and actions elicited by a fear-arousing stimulus. Nat. Neurosci. 3, 74-79. doi: 10.1038/71145

Asan, E. (1998). The catecholaminergic innervation of the rat amygdala. Adv. Anat. Embryol. Cell Biol. 142, 1-118. doi: 10.1007/978-3-642-72085-7

Aston-Jones, G., Ennis, M., Pieribone, V. A., Nickell, W. T., and Shipley, M. T. (1986). The brain nucleus locus coeruleus: restricted afferent control of a broad efferent network. Science 234, 734-737. doi: 10.1126/science.3775363

Banerjee, A., Shen, P.-J. J., Ma, S., Bathgate, R. A. D., and Gundlach, A. L. (2010). Swim stress excitation of nucleus incertus and rapid induction of relaxin3 expression via CRF1 activation. Neuropharmacology 58, 145-155. doi: 10. 1016/j.neuropharm.2009.06.019

Benarroch, E. E. (2015). The amygdala: functional organization and involvement in neurologic disorders. Neurology 84, 313-324. doi: 10.1212/WNL. 0000000000001171

Bennett, R. G., Heimann, D. G., and Hamel, F. G. (2009). Degradation of relaxin family peptides by insulin-degrading enzyme. Ann. N Y Acad. Sci. 1160, 38-41. doi: 10.1111/j.1749-6632.2008.03782.x

Bienvenu, T. C. M., Busti, D., Micklem, B. R., Mansouri, M., Magill, P. J., Ferraguti, F., et al. (2015). Large intercalated neurons of amygdala relay noxious sensory information. J. Neurosci. 35, 2044-2057. doi: 10.1523/JNEUROSCI.1323-14. 2015

Bittencourt, J. C., and Sawchenko, P. E. (2000). Do centrally administered neuropeptides access cognate receptors? an analysis in the central corticotropin-releasing factor system. J. Neurosci. 20, 1142-1156.

Bocchio, M., Fucsina, G., Oikonomidis, L., McHugh, S. B., Bannerman, D. M., Sharp, T., et al. (2015). Increased serotonin transporter expression reduces fear and recruitment of parvalbumin interneurons of the amygdala. Neuropsychopharmacology 40, 3015-3026. doi: 10.1038/npp. 2015.157

Boels, K., Hermans-Borgmeyer, I., and Schaller, H. C. (2004). Identification of a mouse orthologue of the G-protein-coupled receptor SALPR and its expression in adult mouse brain and during development. Dev. Brain Res. 152, 265-268. doi: 10.1016/j.devbrainres.2004.06.002

Bonn, M., Schmitt, A., Lesch, K.-P., Van Bockstaele, E. J., and Asan, E. (2013). Serotonergic innervation and serotonin receptor expression of NPY-producing neurons in the rat lateral and basolateral amygdaloid nuclei. Brain Struct. Funct. 218, 421-435. doi: 10.1007/s00429-012-0406-5

Bosker, F. J., Cremers, T. I., Jongsma, M. E., Westerink, B. H., Wikström, H. V., and den Boer, J. A. (2001). Acute and chronic effects of citalopram on postsynaptic 5-hydroxytryptamine $(1 \mathrm{~A})$ receptor-mediated feedback: a microdialysis study in the amygdala. J. Neurochem. 76, 1645-1653. doi: 10.1046/j.1471-4159.2001. 00194.x
Jaume I P1·1A2014-06 (AMS-P); FP7-PEOPLE-IRSES PIRSESGA-2012-318997 NEUREN Project (ALG, FEO-B); NHMRC (Australia) Grants 1005985, 1005988 and 1067522 (ALG); and Brain and Behavior Research Foundation (USA) NARSAD Independent Investigator Award (ALG).

Brown, R. E., and McKenna, J. T. (2015). Turning a negative into a positive ascending GABAergic control of cortical activation and arousal. Front. Neurol. 6:135. doi: 10.3389/fneur.2015.00135

Canteras, N. S., and Swanson, L. W. (1992). Projections of the ventral subiculum to the amygdala, septum and hypothalamus: a PHAL anterograde tracttracing study in the rat. J. Comp. Neurol. 324, 180-194. doi: 10.1002/cne.9032 40204

Carlsson, A., and Lindqvist, M. (1963). Effect of chlorpromazine or haloperidol on formation of 3-methoxytyramine and normetanephrine in mouse brain. Acta Pharmacol. Toxicol. (Copenh). 20, 140-144. doi: 10.1111/j.1600-0773. 1963.tb01730.x

Chen, F. J., and Sara, S. J. (2007). Locus coeruleus activation by foot shock or electrical stimulation inhibits amygdala neurons. Neuropharmacology 144, 472-481. doi: 10.1016/j.neuroscience.2006.09.037

Christianson, J. P., Ragole, T., Amat, J., Greenwood, B. N., Strong, P. V., Paul, E. D., et al. (2010). 5-hydroxytryptamine $2 \mathrm{C}$ receptors in the basolateral amygdala are involved in the expression of anxiety after uncontrollable traumatic stress. Biol. Psychiatry 67, 339-345. doi: 10.1016/j.biopsych.2009. 09.011

Chu, H.-Y., Ito, W., Li, J., and Morozov, A. (2012). Target-specific suppression of GABA release from parvalbumin interneurons in the basolateral amygdala by dopamine. J. Neurosci. 32, 14815-14820. doi: 10.1523/JNEUROSCI.2997-12. 2012

Clark, S. D., Duangdao, D. M., Schulz, S., Zhang, L., Liu, X., Xu, Y.-L., et al. (2011). Anatomical characterization of the neuropeptide $S$ system in the mouse brain by in situ hybridization and immunohistochemistry. J. Comp. Neurol. 519, 1867-1893. doi: 10.1002/cne.22606

Creese, I., Burt, D. R., and Snyder, S. H. (1976). Dopamine receptor binding predicts clinical and pharmacological potencies of antischizophrenic drugs. Science 192, 481-483. doi: 10.1126/science.3854

Davis, M. (2000). The role of the amygdala in conditioned and unconditioned fear and anxiety. The amygdala: a functional analysis, ed. J. P. Aggleton Available online at: https://scholar.google.com/scholar_lookup?title= The role of the amygdala in conditioned and unconditioned fear and anxiety\&author $=M$ Davis\&publication_year=2000\&citation_inbook_title= The amygdala\#0. Accessed on June 24, 2015.

Davis, T. P., and Konings, P. N. (1993). Peptidases in the CNS: formation of biologically active, receptor-specific peptide fragments. Crit. Rev. Neurobiol. 7, 163-174.

Debiec, J., Bush, D. E., and LeDoux, J. E. (2011). Noradrenergic enhancement of reconsolidation in the amygdala impairs extinction of conditioned fear in rats-a possible mechanism for the persistence of traumatic memories in PTSD. Depress. Anxiety 28, 186-193. doi: 10.1002/da.20803

Debiec, J., and LeDoux, J. E. (2006). Noradrenergic signaling in the amygdala contributes to the reconsolidation of fear memory: treatment implications for PTSD. Ann. N Y Acad. Sci. 1071, 521-524. doi: 10.1196/annals. 1364.056

Dinnissen, M., Dietrich, A., van den Hoofdakker, B. J., and Hoekstra, P. J. (2015). Clinical and pharmacokinetic evaluation of risperidone for the management of autism spectrum disorder. Expert Opin. Drug Metab. Toxicol. 11, 111-124. doi: $10.1517 / 17425255.2015 .981151$

Duggan, A. W., Hope, P. J., Jarrott, B., Schaible, H. G., and Fleetwood-Walker, S. M. (1990). Release, spread and persistence of immunoreactive neurokinin A in the dorsal horn of the cat following noxious cutaneous stimulation. Studies with antibody microprobes. Neuroscience 35, 195-202. doi: 10.1016/03064522(90)90134-p

Duggan, A. W., Schaible, H. G., Hope, P. J., and Lang, C. W. (1992). Effect of peptidase inhibition on the pattern of intraspinally released immunoreactive substance P detected with antibody microprobes. Brain Res. 579, 261-269. doi: 10.1016/0006-8993(92)90059-i 
Ehrlich, I., Humeau, Y., Grenier, F., Ciocchi, S., Herry, C., and Lüthi, A. (2009). Amygdala inhibitory circuits and the control of fear memory. Neuron 62, 757-771. doi: 10.1016/j.neuron.2009.05.026

Ferguson, J. N., Aldag, J. M., Insel, T. R., and Young, L. J. (2001). Oxytocin in the medial amygdala is essential for social recognition in the mouse. J. Neurosci. 21, 8278-8285.

Ganella, D. E., Callander, G. E., Ma, S., Bye, C. R., Gundlach, A. L., and Bathgate, R. A. D. (2013). Modulation of feeding by chronic rAAV expression of a relaxin-3 peptide agonist in rat hypothalamus. Gene Ther. 20, 703-716. doi: 10. 1038 /gt.2012.83

Gorman, J. M. (2003). Treating generalized anxiety disorder. J. Clin. Psychiatry 64, 24-29.

Haugaard-Kedström, L. M., Shabanpoor, F., Hossain, M. A., Clark, R. J., Ryan, P. J., Craik, D. J., et al. (2011). Design, synthesis and characterization of a singlechain peptide antagonist for the relaxin-3 receptor RXFP3. J. Am. Chem. Soc. 133, 4965-4974. doi: 10.1021/ja110567j

Jolkkonen, E., and Pitkänen, A. (1998). Intrinsic connections of the rat amygdaloid complex: projections originating in the central nucleus. J. Comp. Neurol. 395, 53-72. doi: 10.1002/(sici)1096-9861(19980525)395:1<53::aid-cne5>3.0.co;2-g

Justice, N. J., Yuan, Z. F., Sawchenko, P. E., and Vale, W. (2008). Type 1 corticotropin-releasing factor receptor expression reported in BAC transgenic mice: implications for reconciling ligand-receptor mismatch in the central corticotropin-releasing factor system. J. Comp. Neurol. 511, 479-496. doi: 10. 1002/cne. 21848

Kawahara, H., Yoshida, M., Yokoo, H., Nishi, M., and Tanaka, M. (1993). Psychological stress increases serotonin release in the rat amygdala and prefrontal cortex assessed by in vivo microdialysis. Neurosci. Lett. 162, 81-84. doi: 10.1016/0304-3940(93)90565-3

Kuo, W. L., Montag, A. G., and Rosner, M. R. (1993). Insulin-degrading enzyme is differentially expressed and developmentally regulated in various rat tissues. Endocrinology 132, 604-611. doi: 10.1210/en.132.2.604

LeDoux, J. E. (2000). Emotion circuits in the brain. Annu. Rev. Neurosci. 23, 155-184. doi: 10.1146/annurev.neuro.23.1.155

Lenglos, C., Mitra, A., Guevremont, G., and Timofeeva, E. (2013). Sex differences in the effects of chronic stress and food restriction on body weight gain and brain expression of CRF and relaxin-3 in rats. Genes Brain Behav. 12, 370-387. doi: $10.1111 / \mathrm{gbb} .12028$

Lenglos, C., Mitra, A., Guèvremont, G., and Timofeeva, E. (2014). Regulation of expression of relaxin-3 and its receptor RXFP3 in the brain of diet-induced obese rats. Neuropeptides 48, 119-132. doi: 10.1016/j.npep.2014.02.002

Lesting, J., Daldrup, T., Narayanan, V., Himpe, C., Seidenbecher, T., and Pape, H.-C. (2013). Directional theta coherence in prefrontal cortical to amygdalohippocampal pathways signals fear extinction. PLoS One 8:e77707. doi: 10. 1371/journal.pone.0077707

Lesting, J., Narayanan, R. T., Kluge, C., Sangha, S., Seidenbecher, T., and Pape, H. C. (2011). Patterns of coupled theta activity in amygdala-hippocampalprefrontal cortical circuits during fear extinction. PLoS One 6:e21714. doi: 10. 1371/journal.pone.0021714

Liu, C., Eriste, E., Sutton, S., Chen, J., Roland, B., Kuei, C., et al. (2003). Identification of relaxin-3/INSL7 as an endogenous ligand for the orphan Gprotein-coupled receptor GPCR135. J. Biol. Chem. 278, 50754-50764. doi: 10. 1074/jbc.m308995200

Loughlin, S. E., and Fallon, J. H. (1983). Dopaminergic and non-dopaminergic projections to amygdala from substantia nigra and ventral tegmental area. Brain Res. 262, 334-338. doi: 10.1016/0006-8993(83)91029-6

Ma, S., Blasiak, A., Olucha-Bordonau, F. E., Verberne, A. J., and Gundlach, A. L. (2013). Heterogeneous responses of nucleus incertus neurons to corticotrophin-releasing factor and coherent activity with hippocampal theta rhythm in the rat. J. Physiol. 591, 3981-4001. doi: 10.1113/jphysiol.2013. 254300

Ma, S., Bonaventure, P., Ferraro, T., Shen, P. J., Burazin, T. C., Bathgate, R. A., et al. (2007). Relaxin-3 in GABA projection neurons of nucleus incertus suggests widespread influence on forebrain circuits via G-protein-coupled receptor135 in the rat. Neuroscience 144, 165-190. doi: 10.1016/j.neuroscience.2006. 08.072

Ma, S., and Gundlach, A. L. (2015). Ascending control of arousal and motivation: role of nucleus incertus and its peptide neuromodulators in behavioural responses to stress. J. Neuroendocrinol. 27, 457-467. doi: 10.1111/jne.12259
Ma, S., Olucha-Bordonau, F. E., Hossain, M. A., Lin, F., Kuei, C., Liu, C., et al. (2009). Modulation of hippocampal theta oscillations and spatial memory by relaxin-3 neurons of the nucleus incertus. Learn. Mem. 16, 730-742. doi: 10. 1101/lm.1438109

Mailman, R. B., and Murthy, V. (2010). Third generation antipsychotic drugs: partial agonism or receptor functional selectivity? Curr. Pharm. Des. 16, 488-501. doi: 10.2174/138161210790361461

Martínez-García, F., Novejarque, A., Gutiérrez-Castellanos, N., and Lanuza, E. (2012). "Piriform cortex and amygdala," in The Mouse Nervous System, eds G. Paxinos, C. Watson, and L. Puelles (San Diego CA: Elsevier Academic Press), $140-172$.

McDonald, A. J. (1998). Cortical pathways to the mammalian amygdala. Prog. Neurobiol. 55, 257-332. doi: 10.1016/s0301-0082(98) 00003-3

McDonald, A., and Mascagni, F. (2001). Colocalization of calcium-binding proteins and GABA in neurons of the rat basolateral amygdala. Neuroscience 105, 681-693. doi: 10.1016/s0306-4522(01)00214-7

McGowan, B. M., Stanley, S. A., Smith, K. L., Minnion, J. S., Donovan, J., Thompson, E. L., et al. (2006). Effects of acute and chronic relaxin-3 on food intake and energy expenditure in rats. Regul. Pept. 136, 72-77. doi: 10.1016/j. regpep.2006.04.009

McGowan, B. M., Stanley, S. A., Smith, K. L., White, N. E., Connolly, M. M., Thompson, E. L., et al. (2005). Central relaxin-3 administration causes hyperphagia in male Wistar rats. Endocrinology 146, 3295-3300. doi: 10. 1210/en.2004-1532

Meis, S., Bergado-Acosta, J. R., Yanagawa, Y., Obata, K., Stork, O., and Munsch, T. (2008). Identification of a neuropeptide $S$ responsive circuitry shaping amygdala activity via the endopiriform nucleus. PLoS One 3:e2695. doi: 10. 1371/journal.pone.0002695

Mo, B., Feng, N., Renner, K., and Forster, G. (2008). Restraint stress increases serotonin release in the central nucleus of the amygdala via activation of corticotropin-releasing factor receptors. Brain Res. Bull. 76, 493-498. doi: 10. 1016/j.brainresbull.2008.02.011

Nader, K., and LeDoux, J. (1999). The dopaminergic modulation of fear: quinpirole impairs the recall of emotional memories in rats. Behav. Neurosci. 113, 152-165. doi: 10.1037/0735-7044.113.1.152

Nader, K., Majidishad, P., Amorapanth, P., and LeDoux, J. E. (2001). Damage to the lateral and central, but not other, amygdaloid nuclei prevents the acquisition of auditory fear conditioning. Learn. Mem. 8, 156-163. doi: 10. 1101/lm.38101

Nuñez, A., Cervera-Ferri, A., Olucha-Bordonau, F., Ruiz-Torner, A., and Teruel, V. (2006). Nucleus incertus contribution to hippocampal theta rhythm generation. Eur. J. Neurosci. 23, 2731-2738. doi: 10.1111/j.1460-9568.2006. 04797.x

O'Keefe, J. (1993). Hippocampus, theta and spatial memory. Curr. Opin. Neurobiol. 3, 917-924. doi: 10.1016/0959-4388(93)90163-s

Olucha-Bordonau, F. E., Fortes-Marco, L., Otero-García, M., Lanuza, E., and Martínez-García, F. (2014). "The amygdala structure and function," in The Rat Nervous System, IV Edn. ed. G. Paxinos (Cambridge, MA: Academic Press), 441-490.

Olucha-Bordonau, F. E., Otero-García, M., Sánchez-Pérez, A. M., Núñez, A., Ma, S., Gundlach, A. L., et al. (2012). Distribution and targets of the relaxin-3 innervation of the septal area in the rat. J. Comp. Neurol. 520, 1903-1939. doi: $10.1002 /$ cne. 23018

Olucha-Bordonau, F. E., Teruel, V., Barcia-Gonzalez, J., Ruiz-Torner, A., Valverde-Navarro, A. A., Martinez-Soriano, F., et al. (2003). Cytoarchitecture and efferent projections of the nucleus incertus of the rat. J. Comp. Neurol. 464, 62-97. doi: 10.1002/cne.10774

Orzeł-Gryglewska, J., Matulewicz, P., and Jurkowlaniec, E. (2015). Brainstem system of hippocampal theta induction: the role of the ventral tegmental area. Synapse 69, 553-575. doi: 10.1002/syn.21843

Pape, H. C., Jüngling, K., Seidenbecher, T., Lesting, J., and Reinscheid, R. K. (2010). Neuropeptide $S$ : a transmitter system in the brain regulating fear and anxiety. Neuropharmacology 58, 29-34. doi: 10.1016/j.neuropharm.2009. 06.001

Paré, D., Collins, D. R., and Pelletier, J. G. (2002). Amygdala oscillations and the consolidation of emotional memories. Trends Cogn. Sci. 6, 306-314. doi: 10. 1016/s1364-6613(02)01924-1 
Paré, D., Quirk, G. J., and Ledoux, J. E. (2004). New vistas on amygdala networks in conditioned fear. J. Neurophysiol. 92, 1-9. doi: 10.1152/jn.00153.2004

Paxinos, G. G., and Watson, C. (2014). The Rat Brain in Stereotaxic Coordinates. San Diego, CA: Academic Press.

Paxinos, G., Watson, C., Carrive, P., Kirkcaldie, M., and Ashwell, K. (2008). Chemoarchitectonic Atlas of the Rat Brain. 2nd Edn. San Diego: Academic Press.

Pereira, C. W., Santos, F. N., Sánchez-Pérez, A. M., Otero-García, M., Marchioro, M., Ma, S., et al. (2013). Electrolytic lesion of the nucleus incertus retards extinction of auditory conditioned fear. Behav. Brain Res. 247, 201-210. doi: 10. 1016/j.bbr.2013.03.025

Pérez de la Mora, M., Hernández-Gómez, A. M., Arizmendi-García, Y., Jacobsen, K. X., Lara-García, D., Flores-Gracia, C., et al. (2007). Role of the amygdaloid cholecystokinin (CCK)/gastrin-2 receptors and terminal networks in the modulation of anxiety in the rat. Effects of CCK-4 and CCK-8S on anxietylike behaviour and [3H]GABA release. Eur. J. Neurosci. 26, 3614-3630. doi: 10. 1111/j.1460-9568.2007.05963.x

Pérez de la Mora, M., Jacobsen, K. X., Crespo-Ramírez, M., Flores-Gracia, C., and Fuxe, K. (2008). Wiring and volume transmission in rat amygdala. Implications for fear and anxiety. Neurochem. Res. 33, 1618-1633. doi: 10.1007/s11064-0089722-9

Phelps, E. A. (2006). Emotion and cognition: insights from studies of the human amygdala. Annu. Rev. Psychol. 57, 27-53. doi: 10.1146/annurev.psych.56. 091103.070234

Pitkänen, A., Savander, V., and LeDoux, J. E. (1997). Organization of intraamygdaloid circuitries in the rat: an emerging framework for understanding functions of the amygdala. Trends Neurosci. 20, 517-523. doi: 10.1016/s01662236(97)01125-9

Pro-Sistiaga, P., Mohedano-Moriano, A., Ubeda-Bañon, I., Del Mar ArroyoJimenez, M., Marcos, P., Artacho-Pérula, E., et al. (2007). Convergence of olfactory and vomeronasal projections in the rat basal telencephalon. J. Comp. Neurol. 504, 346-362. doi: 10.1002/cne.21455

Quirk, G. J., Likhtik, E., Pelletier, J. G., and Pare, D. (2003). Stimulation of medial prefrontal cortex decreases the responsiveness of central amygdala output neurons. J. Neurosci. 23, 8800-8807.

Ryan, P. J., Buchler, E., Shabanpoor, F., Hossain, M. A., Wade, J. D., Lawrence, A. J., et al. (2013a). Central relaxin-3 receptor (RXFP3) activation decreases anxiety- and depressive-like behaviours in the rat. Behav. Brain Res. 244, 142-151. doi: 10.1016/j.bbr.2013.01.034

Ryan, P. J., Kastman, H. E., Krstew, E. V., Rosengren, K. J., Hossain, M. A., Churilov, L., et al. (2013b). Relaxin-3/RXFP3 system regulates alcohol-seeking. Proc. Natl. Acad. Sci. U S A 110, 20789-20794. doi: 10.1073/pnas.1317807110

Sakanaka, M., Shibasaki, T., and Lederis, K. (1986). Distribution and efferent projections of corticotropin-releasing factor-like immunoreactivity in the rat amygdaloid complex. Brain Res. 382, 213-238. doi: 10.1016/00068993(86)91332-6

Sakanaka, M., Shibasaki, T., and Lederis, K. (1987). Corticotropin releasing factorlike immunoreactivity in the rat brain as revealed by a modified cobalt-glucose oxidase-diaminobenzidine method. J. Comp. Neurol. 260, 256-298. doi: 10. 1002/cne.902600209

Scalia, F., and Winans, S. S. (1975). The differential projections of the olfactory bulb and accessory olfactory bulb in mammals. J. Comp. Neurol. 161, 31-55. doi: 10.1002/cne.901610105

Schmitt, O., Eipert, P., Philipp, K., Kettlitz, R., Fuellen, G., and Wree, A. (2012). The intrinsic connectome of the rat amygdala. Front. Neural Circuits 6:81. doi: $10.3389 /$ fncir.2012.00081

Schumann, C. M., and Amaral, D. G. (2006). Stereological analysis of amygdala neuron number in autism. J. Neurosci. 26, 7674-7679. doi: 10.1523/jneurosci. 1285-06.2006

Schumann, C. M., Hamstra, J., Goodlin-Jones, B. L., Lotspeich, L. J., Kwon, H., Buonocore, M. H., et al. (2004). The amygdala is enlarged in children but not adolescents with autism; the hippocampus is enlarged at all ages. J. Neurosci. 24, 6392-6401. doi: 10.1523/jneurosci.1297-04.2004

Seidenbecher, T., Laxmi, T. R., Stork, O., and Pape, H. C. (2003). Amygdalar and hippocampal theta rhythm synchronization during fear memory retrieval. Science 301, 846-850. doi: 10.1126/science. 1085818

Shabanpoor, F., Akhter Hossain, M., Ryan, P. J., Belgi, A., Layfield, S., Kocan, M., et al. (2012). Minimization of human relaxin-3 leading to high-affinity analogues with increased selectivity for relaxin-family peptide 3 receptor (RXFP3) over RXFP1. J. Med. Chem. 55, 1671-1681. doi: 10.1021/jm201505p

Sheehan, D. V., Raj, B. A., Trehan, R. R., and Knapp, E. L. (1993). Serotonin in panic disorder and social phobia. Int. Clin. Psychopharmacol. 8, 63-77. doi: 10. 1097/00004850-199311002-00010

Sierra-Mercado, D., Padilla-Coreano, N., and Quirk, G. J. (2011). Dissociable roles of prelimbic and infralimbic cortices, ventral hippocampus and basolateral amygdala in the expression and extinction of conditioned fear. Neuropsychopharmacology 36, 529-538. doi: 10.1038/npp 2010.184

Smith, H. R., and Porrino, L. J. (2008). The comparative distributions of the monoamine transporters in the rodent, monkey and human amygdala. Brain Struct. Funct. 213, 73-91. doi: 10.1007/s00429-008-0176-2

Smith, C. M., Ryan, P. J., Hosken, I. T., Ma, S., and Gundlach, A. L. (2011). Relaxin3 systems in the brain-The first 10 years. J. Chem. Neuroanat. 42, 262-275. doi: 10.1016/j.jchemneu.2011.05.013

Smith, C. M., Shen, P. J., Banerjee, A., Bonaventure, P., Ma, S., Bathgate, R. A. D., et al. (2010). Distribution of relaxin-3 and RXFP3 within arousal, stress, affective and cognitive circuits of mouse brain. J. Comp. Neurol. 518, 4016-4045. doi: 10.1002/cne.22442

Smith, C. M., Walker, A. W., Hosken, I. T., Chua, B. E., Zhang, C., Haidar, M., et al. (2014). Relaxin-3/RXFP3 networks: an emerging target for the treatment of depression and other neuropsychiatric diseases? Front. Pharmacol. 5:46. doi: 10.3389/fphar.2014.00046

Steinbusch, H. W. (1981). Distribution of serotonin-immunoreactivity in the central nervous system of the rat-cell bodies and terminals. Neuroscience 6 , 557-618. doi: 10.1016/0306-4522(81)90146-9

Sun, N., and Cassell, M. D. (1993). Intrinsic GABAergic neurons in the rat central extended amygdala. J. Comp. Neurol. 330, 381-404. doi: 10.1002/cne.903 300308

Sutton, S. W., Bonaventure, P., Kuei, C., Roland, B., Chen, J., Nepomuceno, D., et al. (2004). Distribution of G-protein-coupled receptor (GPCR)135 binding sites and receptor mRNA in the rat brain suggests a role for relaxin-3 in neuroendocrine and sensory processing. Neuroendocrinology 80, 298-307. doi: 10.1159/000083656

Swanson, L. W., Sawchenko, P. E., Rivier, J., and Vale, W. W. (1983). Organization of ovine corticotropin-releasing factor immunoreactive cells and fibers in the rat brain: an immunohistochemical study. Neuroendocrinology 36, 165-186. doi: $10.1159 / 000123454$

Tanaka, M., Iijima, N., Miyamoto, Y., Fukusumi, S., Itoh, Y., Ozawa, H., et al. (2005). Neurons expressing relaxin 3/INSL 7 in the nucleus incertus respond to stress. Eur. J. Neurosci. 21, 1659-1670. doi: 10.1111/j.1460-9568.2005. 03980.x

Thureson-Klein, A., Klein, R. L., and Zhu, P. C. (1986). Exocytosis from large dense cored vesicles as a mechanism for neuropeptide release in the peripheral and central nervous system. Scan. Electron Microsc. Pt. 1, 179-187.

Trainor, B. C., Crean, K. K., Fry, W. H. D., and Sweeney, C. (2010). Activation of extracellular signal-regulated kinases in social behavior circuits during resident-intruder aggression tests. Neuroscience 165, 325-336. doi: 10.1016/j. neuroscience.2009.10.050

Van Pett, K., Viau, V., Bittencourt, J. C., Chan, R. K., Li, H. Y., Arias, C., et al. (2000). Distribution of mRNAs encoding CRF receptors in brain and pituitary of rat and mouse. J. Comp. Neurol. 428, 191-212. doi: 10.1002/10969861(20001211)428:2<191::aid-cne1>3.0.co;2-u

Vertes, R. P. (2004). Differential projections of the infralimbic and prelimbic cortex in the rat. Synapse 51, 32-58. doi: 10.1002/syn.10279

Vertes, R. P., Fortin, W. J., and Crane, A. M. (1999). Projections of the median raphe nucleus in the rat. J. Comp. Neurol. 407, 555-582. doi: 10.1002/(sici)10969861(19990517)407:4<555::aid-cne7>3.0.co;2-e

Vertes, R. P., and Kocsis, B. (1994). Projections of the dorsal raphe nucleus to the brainstem: PHA-L analysis in the rat. J. Comp. Neurol. 340, 11-26. doi: 10. 1002/cne. 903400103

Watanabe, Y., Tsujimura, A., Takao, K., Nishi, K., Ito, Y., Yasuhara, Y., et al. (2011). Relaxin-3-deficient mice showed slight alteration in anxiety-related behavior. Front. Behav. Neurosci. 5:50. doi: 10.3389/fnbeh.2011.00050

Wilkinson, T. N., and Bathgate, R. A. D. (2007). The evolution of the relaxin peptide family and their receptors. Adv. Exp. Med. Biol. 612, 1-13. doi: 10. 1007/978-0-387-74672-2_1 
Wolff, S. B. E., Gründemann, J., Tovote, P., Krabbe, S., Jacobson, G. A., Müller, C., et al. (2014). Amygdala interneuron subtypes control fear learning through disinhibition. Nature 509, 453-458. doi: 10.1038/nature 13258

Xu, Y.-L., Reinscheid, R. K., Huitron-Resendiz, S., Clark, S. D., Wang, Z., Lin, S. H., et al. (2004). Neuropeptide S: a neuropeptide promoting arousal and anxiolytic-like effects. Neuron 43, 487-497. doi: 10.1016/j.neuron.2004. 08.005

Yokoyama, M., Suzuki, E., Sato, T., Maruta, S., Watanabe, S., and Miyaoka, H. (2005). Amygdalic levels of dopamine and serotonin rise upon exposure to conditioned fear stress without elevation of glutamate. Neurosci. Lett. 379, 37-41. doi: 10.1016/j.neulet.2004.12.047

Zhang, C., Chua, B. E., Yang, A., Shabanpoor, F., Hossain, M. A., Wade, J. D., et al. (2015). Central relaxin-3 receptor (RXFP3) activation reduces elevated, but not basal, anxiety-like behaviour in C57BL/6J mice. Behav. Brain Res. 292, 125-132. doi: 10.1016/j.bbr.2015.06.010
Zhu, P. C., Thureson-Klein, A., and Klein, R. L. (1986). Exocytosis from large dense cored vesicles outside the active synaptic zones of terminals within the trigeminal subnucleus caudalis: a possible mechanism for neuropeptide release. Neuroscience 19, 43-54. doi: 10.1016/0306-4522(86)90004-7

Conflict of Interest Statement: The authors declare that the research was conducted in the absence of any commercial or financial relationships that could be construed as a potential conflict of interest.

Copyright (c) 2016 Santos, Pereira, Sánchez-Pérez, Otero-García, Ma, Gundlach and Olucha-Bordonau. This is an open-access article distributed under the terms of the Creative Commons Attribution License (CC BY). The use, distribution and reproduction in other forums is permitted, provided the original author(s) or licensor are credited and that the original publication in this journal is cited, in accordance with accepted academic practice. No use, distribution or reproduction is permitted which does not comply with these terms. 